\title{
LOS GASTOS QUE DETERMINAN LA CUANTIA DE LAS CONTRIBUCIONES ESPECIALES
}

$336.8(094.9)$

por

\section{Francisco Suárez Morán}

Secretario general del Excmo. Ayuntamiento de Vigo

SUMARIO: I. LA INTERPRETACION DEL ARTICULO 454 DE LA LEY DE REGIMEN LOCAL.-II. LAS CONTRIBUCIONES ESPECIALES Y LOS DEMAS TRIBUTOS.-III. EL FIN DE LAS CONTRIBUCIONES ESPECIALES Y EL ENRIQUECIMIENTO SIN CAUSA.IV. EL FIN, CRITERIO PREVALENTE EN LA INTERPRETACION DE LA NORMA. LA LLAMADA ANALOGIA EXTENSIVA. CRITERIOS JURISPRUDENCIALES.-V. LAS CONTRIBUCIONES ESPECIALES, LA DESVIACION DE PODER Y LAS SUBVENCIONES DE MERA LIBERALIDAD.-VI. EL EXTRAÑO REGIMEN DE SUBVENCIONES Y LA CUANTIA DE LAS CONTRIBUCIONES ESPECIALES.-VII. COMPATIBILIDAD DE LAS CONTRIBUCIONES ESPECIALES Y LAS EXPROPIACIONES POR UTILIDAD PUBLICA.-VIII. CONCLUSIONES.

\section{LA INTERPRETACION DEL ARTICULO 454}

DE LA LEY DE REGIMEN LOCAL

Uno de los motivos fundamentales de la penuria de las Haciendas locales se halla sin duda en los no fáciles mecanismos ideados por el legislador para exaccionar las contribuciones especiales, lo que dificulta utilizar estos medios de financiación de las obras municipales con la frecuencia deseable ante el temor de posibles defectos, particularmente cuando de aumento de valor se trata, que motivan rectificaciones de los Tribunales con las dilaciones obligadas en su ejecución. 
En los últimos años se han publicado meritorios trabajos sobre algunos de los múltiples problemas que la jurisprudencia ha tratado de resolver, no siempre con criterio uniforme, y el propio legislador ha intentado por dos veces reformas que hasta la fecha han carecido de significación práctica (1). No obstante, en ésta como en tantas otras instituciones no es fácil llegar a soluciones acertadas si con un esfuerzo cartesiano no se parte de ideas claras y distintas, poniendo de manifiesto los principios que subyacen en la frondosidad legislativa, inicialmente vigorosos, pero que el transcurso del tiempo ha enmascarado hasta llegar a la complejidad actual, a lo que parece con pretensiones de pervivencia.

Concebidas como ingresos de economía pública, sólo el hecho imponible permitiría diferenciarlas de otras exacciones municipales. La primera consecuencia es obvia: la interpretación analógica y la extensiva son incompatibles con el régimen tributario, como de modo uniforme ha establecido la jurisprudencia del Tribunal Supremo. Por tanto, en principio se habría de mantener que el costo de las obras se integra por los distintos conceptos que en su literalidad comprende el artículo 454 de la Ley de Régimen local. Si se debe incluir el "valor de los terrenos que las obras o instalaciones hubiesen de ocupar permanentemente», no sería lícito, invocando el principio de Derecho civil de que superficies solo cedit, incluir el valor de lo edificado, que deberá correr a cargo de la economía municipal, cualquiera que sea el importe que pueda alcanzar y la repercusión que tenga en el aumento de valor.

Tal interpretación obedece a razones históricas bien definidas, alteradas en algunos países sólo en la Edad Moderna, y que fueron motivo importante de la grave convulsión que motivó la independencia de Estados Unidos: «La imposición de tributos sin representación es tiranía».

El temor a las veleidades absolutistas del Ejecutivo, el respeto al «sagrado derecho de propiedad» y las ideas liberales -el dinero fructifica en el bolsillo del pueblo, diría Gladstone- fueron los motivos que determinaron como atribución exclusiva del órgano legislativo todo lo relativo a impuestos, estableciéndose así un con-

(1) Leyes 85/1962, de 24 de diciembre, y 48/1966, de 23 de julio. Aunque esta última y el artículo $50^{\circ}$ de la anterior puedan tener carácter de Ley de Bases, la jurisprudencia y la doctrina del Consejo de Estado admiten la vigencia inmediata de ciertos preceptos concretos que al articularse deben ser transcritos sin otra opción posible. 
trol eficacísimo sobre el Gobierno que no se podría resquebrajar mediante la interpretación analógica o extensiva.

\section{LAS CONTRIBUCIONES ESPECIALES Y LOS DEMAS TRIBUTOS}

Sin necesidad de referirnos a la profunda crisis que el transcurso del tiempo ha originado en la triple motivación indicada, será suficiente a nuestro propósito desvelar la singularidad de las contribuciones especiales frente a los demás tributos, pues la propia denominación indica que su «especialidad" las diversifica del régimen tributario general.

Conforme a la Ley 230, de 28 de diciembre de 1963, se podrúan establecer esquemáticamente las siguientes diferencias:

a) Por el concepto: Tasas e impuestos son retribuciones al Estado o ente público por prestación de servicios divisibles o indivisibles, respectivamente.

Las contribuciones especiales no son retribuciones de ningún servicio, sino absorción de un beneficio especial o incremento de valor creado por una inversión municipal con la pasividad del titular de los bienes.

b) Por el título que las legitima: Tasas e impuestos se derivan de la soberanía del Estado que los crea o autoriza.

En las contribuciones especiales sería innecesario acudir a la soberanía del Estado, ya que es suficiente el principio general de Derecho que en caso de enriquecimiento sin causa obliga a la restitutio in integrum.

c) Por el fin: Los ingresos por tasas e impuestos se destinan a satisfacer necesidades generales, excepto cuando en virtud de una Ley ciertos ingresos se afectan a finalidades concretas.

Las contribuciones especiales evitan que los ingresos públicos, apartándose de su fin propio, se destinen en beneficio de determinadas personas. Son un procedimiento para reintegrar a la Hacienda municipal los gastos ocasionados con motivo de ejecución de obras o instalación de servicios en cuanto hayan beneficiado o producido incremento de valor a los titulares de ciertos bienes.

d) Por la cuantía: En las tasas el ingreso no debe exceder del gasto y en los impuestos la cuantía se fija aplicando al objeto del 
gravamen el tipo de imposición. Suponen siempre una detracción del patrimonio del contribuyente, o sea un empobrecimiento.

En las contribuciones especiales el objeto del gravamen -cuantía del beneficio o aumento del valor- es y debe ser igual a la deuda tributaria, no teniendo carácter confiscatorio, sino reintegro de un incremento patrimonial injustificado. No empobrecen al obligado al pago, sino que evitan su enriquecimiento «torticero».

Determinada la cuantía del beneficio o del incremento de valor, queda fijada la deuda tributaria. Los conceptos que integran el gasto sólo tienen importancia indirecta en cuanto las contribuciones especiales no pueden legalmente exceder de la cuantía de la inversión, pero si se excluyen parte de los que son estrictamente necesarios para llevar a efecto la obra o instalar el servicio, se financiarán con ingresos públicos aumentos patrimoniales de determinadas personas.

El rendimiento de cualquier tributo puede aumentarse o disminuirse, graduarse según la capacidad económica del sujeto pasivo o suprimirse por distintas consideraciones ideológicas o por situaciones coyunturales, pero la cuantía de las contribuciones especiales es inmodificable, pues a la altura de nuestro tiempo un principio elemental de justicia exige que los ingresos públicos se inviertan en satisfacer intereses generales y no en enriquecer ciertos patrimonios. Las consecuencias legales de proceder de otro modo, aunque son demasiado obvias, se analizarán oportunamente

\section{EL FIN DE LAS CONTRIBUCIONES ESPECIALES Y EL ENRIQUECIMIENTO SIN CAUSA}

El 16 de julio de 1918, don Augusto GonzÁlez Besada, Ministro de Hacienda del Gabinete Nacional, sometió al Consejo de Ministros el «Proyecto de Ley regulando las exacciones municipales», basado en el de Canalejas de 1910 y que prácticamente fue incorporado al Estatuto Municipal y posteriormente, sin modificaciones apreciable, a la Ley de Régimen local y sus sucesivas modificaciones.

El preámbulo, obra del que fue en su tiempo gran economista español, señor FloRES dE LEMUS, después de examinar el fenómeno anómalo de que con la actividad municipal cientos de millones de pesetas han engrosado los patrimonios particulares de los propie- 
tarios del suelo de nuestras ciudades, se refiere a la desnaturalización de los arbitrios municipales que tienen por justificación única atender los servicios públicos, y en ningún caso enriquecer a determinadas personas. La situación resultaba más conflictiva e injusta atendiendo al origen de los ingresos que se destinaban a tales fines, al obtenerse «en su mayor parte, a tipos de gran dureza en muchos casos, del proletariado urbano y de las clases inferiores de la clase media, mientras existió el impuesto de consumos, y de esta clase media después de la supresión de tal impuesto; esto es, de gentes que supieron de aquella elevación de capitales ajenos por el aumento que ellos experimentaron en el alquiler de sus viviendas".

Diagnosticada la enfermedad, el tratamiento no podía ofrecer dificultades: si en el proyecto de Canalejas se prohibía imponer gravámenes para favorecer intereses particulares, en el de GoNZÁLEZ BESADA se ampliaría la prohibición a las rentas, y el principio se consigna con esta meridiana claridad: "Las Corporaciones locales no pueden exigir gravámenes ni emplear las rentas de que disponen para las atenciones generales del Municipio en favorecer especialmente intereses económicos particulares».

Prescindiendo de cualquier consideración de tipo demagógico, en este caso estrechamente vinculada a principios elementales de justicia tributaria, las contribuciones especiales se crearon y subsisten a fin de que los ingresos municipales, cualquiera que sea su origen, se destinen íntegramente a las «atenciones generales del Municịpio», principio legitimador de la imposición municipal, y no a generar enriquecimientos patrimoniales injustificados por el origen y finalidad asignada al gasto público, infringiéndose el principio general de Derecho que impide el enriquecimiento sin causa formulado por el Derecho romano, aceptado por la Ley de Partidas y la jurisprudencia civil y contencioso-administrativa del Tribunal Supremo: In re naturae aequm est neminem cum alterius detrimento e injuria fiere locupletiorem (2).

En efecto, las contribuciones especiales, al igual que el enriquecimiento «torticero", requieren:

- Enriquecimiento de un patrimonio, el del obligado al pago.

(2) El dictamen del Consejo de Estado de 5 de octubre de 1947, núm. marginal 83, cita abundante jurisprudencia civil y contencioso-administrativa. Como más recientes pueden verse las sentencias del Tribunal Supremo de 21 de septiembre de 1949 y 1 de abril de 1963, ambas de la jurisdicción contencioso-administrativa. 
- Que sea consecuencia de la correlativa disminución de otro patrimonio, el erario municipal.

- La inexistencia de causa ha planteado diversos problemas doctrinales, pero simplificando y siguiendo los criterios del Tribunal Supremo se puede afirmar que la falta de causa equivale a título suficiente que legitime el desplazamiento patrimonial.

Parece evidente que ningún motivo, jurídica y éticamente aceptable, justifica que los ingresos públicos con la finalidad específica de atender las necesidades de la comunidad local se destinen a incrementar patrimonios particulares, situación agravada por la importancia que aún hoy día tienen en nuestro Derecho fiscal los impuestos indirectos, particularmente en la Hacienda municipal.

La consecuencia insoslayable de la concurrencia de los tres requisitos expuestos es la restitutio in integrum, que comporta la devolución al erario municipal del aumento de valor generado por el gasto público, siempre que exista relación causal entre enriquecimiento y empobrecimiento. La cuantía de la restitución sólo tiene por límite el equivalente enriquecimiento injustificado y en cuanto no lo alcance seguirá actuando el principio de enriquecimiento «torticero».

IV. EL FIN, CRITERIO PREVALENTE

EN LA INTERPRETACION DE LA NORMA.

LA LLAMADA ANALOGIA EXTENSIVA.

CRITERIOS JURISPRUDENCIALES

SANTO TOMÁs afirmó que lex humana est aliquid ordinatum ad finem (3).

I HERING escribió una obra básica en la literatura jurídica con el título de El fin en el Derecho, y recientemente JEAN DABIN señala como principios directivos en la elaboración del Derecho estas dos preguntas: ¿A qué fin tiende la regla de Derecho y por qué procedimiento está llamado a realizarse en su contenido primero y en su ejecución después? (4).

(3) Summa Teologica, I, II, 9, 95, artículo 3.०

(4) Teoria general del Derecho, pág. 202. 
Para el profesor DE CASTRo la interpretación debe buscar en cada caso el fin de la norma, sin olvídar el fin del Derecho, y los fines, «cuando no los manifiesta la misma ley, se encontrarán en los principios jurídicos, morales, nacionales y políticos del Derecho español, conforme a su valor objetivo e interna jerarquía»; y como la «finalidad de la ley no se limita a regular un caso concreto, sino a crear un orden jurídico al servicio del bien común, está justificado doblar la letra de la ley para pasar a su intención, o dejarla como adormecida en los casos que choque con la utilidad común o con los fines superiores"(5).

Villar Palasí matiza esta doctrina al afirmar que si el método teleológico es, según STAMLER puso de relieve, uno de los más fructíferos en el campo del Derecho común, esa fertilidad se acentúa en cuanto se conecta con el Derecho administrativo.

La jurisprudencia del Tribunal Supremo de modo coherente ha seguido este criterio interpretativo, principalmente las Salas de lo Contencioso-administrativo. «La Administración, al margen de normaciones formales, se rige por fines teleológicos inexcusables y por principios indestructibles, que reglan su conducta con tanto o más rigor que las ordenaciones legales», pues «sobre la letra de la ley debe prevalecer siempre el espíritu de la misma como único medio de que el objetivo del Derecho, que en definitiva consiste en la realización de la justicia, se cumpla en beneficio de la seguridad de los fines de la vida del individuo y de la sociedad» (6).

La jurisprudencia ofrece ejemplos significativos de la trascendencia del fin en el ámbito del Derecho administrativo. Definidas las licencias de obras como autorización a un particular para realizar un acto que le está permitido, previa comprobación de las condiciones requeridas, es obvio que sólo la existencia de un precepto obstativo puede válidamente justificar su denegación. Sin embargo, se pueden negar cuando dañan intereses generales de cualquier tipo, aunque no haya precepto específico que imponga la denegación (7).

Resulta de lo expuesto que la doctrina científica y la jurisprudencia aceptan como criterio primario para la interpretación el fin

(5) Derecho civil de España. Tomo I, págs. 503 y sigs.

(6) Sentencias del Tribunal Supremo de 7 de junio de 1972 (Ar. 3.123), 5 de septiembre de 1965, reiterada en la de 20 de septiembre de 1966.

(7) Sentencias del Tribunal Supremo de 17 de diciembre de 1959, 5 de marzo de 1963,15 de octubre de 1966 y 27 de octubre de 1970. 
querido por la Ley, que en el caso de las contribuciones especiales se halla específicamente consignado en el preámbulo citado, interpretación auténtica de la misma.

Las Leyes tributarias no constituyen en este aspecto ninguna excepción, pues el artículo 23 de la Ley General Tributaria establece como norma primaria de interpretación «los criterios admitidos en Derecho». Sin embargo, el artículo 24 prohibe «la analogía para extender más allá de sus términos estrictos el ámbito del hecho imponible o el de las exenciones o bonificaciones». La inexactitud es claramente manifiesta al confundir en forma lamentable la analogía y la interpretación extensiva, que corrige los términos excesivamente restrictivos de la Ley -minus dixit quam voluit-ampliando la letra de la misma hasta comprender todos los supuestos implícitamente queridos por el legislador o comprendidos en la finalidad de la norma. La analogía, por el contrario, es un procedimiento intermedio entre la pura interpretación y la producción del Derecho para llenar las lagunas de la Ley; se apoya en la Ley, pero presume que el caso de que se trata no está comprendido en la misma. La analogía, como supuesto autónomo, sólo puede ser extensiva en su significado vulgar y al margen de conceptos jurídicos elementales. Si el hecho imponible, las exenciones y bonificaciones se han de interpretar en "sus términos estrictos», las consecuencias obvias serán las siguientes:

- Las contribuciones especiales por aumento de valor no excederán del 90 por 100 del incremento ni del coste total de las obras, instalaciones o servicios determinados en la forma prevista en los artículos 454 y 455, según dispone el artículo 467 de la Ley de Régimen local.

- Para la determinación del costo de las obras, instalaciones o servicios se incluirán siempre a los efectos de esta Ley... b) el valor de los terrenos que las obras o instalaciones hubiesen de ocupar permanentemente, artículo 454 de la Ley de Régimen local.

- Como en el hecho imponible sólo se puede incluir el valor de los terrenos, al atenerse a los "términos estrictos" se debe excluir el valor de las edificaciones accesorias a los terrenos, que serán a cargo exclusivamente del Ayuntamiento.

- Una calle de cuatro metros de ancho, en el barrio antiguo de cualquier ciudad, con pavimento, agua, luz y alcantarillado, se ensancha hasta ocho metros. Las expropiaciones de edificios, único 
gasto de importancia y que puede suponer varios millones de pesetas, serán a cargo del Ayuntamiento, y los propietarios colindantes, con sólo satisfacer el porcentaje legal correspondiente a cuatro metros de nuevo pavimento, el insignificante gasto que pueden suponer los demás conceptos que relaciona el artículo 454 de la Ley de Régimen local y unas modestísimas aceras, podrán duplicar, aproximadamente, la altura de sus edificios, que, además, se revalorizarán al dar frente a una calle con tráfico normal y adecuado soleamiento.

Por este procedimiento, las contribuciones especiales por aumento de valor prácticamente han perdido vigencia en las urbanizaciones que se llevan a efecto en el casco urbano de las ciudades, quedando relegadas a las que se ejecutan en zonas no edificadas, cuando la realidad demuestra que los mayores incremento de valor se originan en el primer supuesto, llegando a adquirir actualmente dichos solares precios escandalosamente exorbitantes, reproduciéndose la situación que en 1918 denunciaba el señor FLORES DE LEMUS para justificar la introducción en nuestro Derecho de las contribuciones especiales.

No es lícito, por el mero hecho de que las contribuciones especiales aparezcan definidas en la Ley General Tributaria y en el sistema fiscal de los Municipios, aplicar en «términos estrictos» su contenido literal, pues a lo dicho sobre su carácter específico, en relación con los demás tributos y la finalidad perseguida, se han de añadir las orientaciones jurisprudenciales que contradicen la doctrina aceptada en materia de contenido exclusivamente tributario.

En efecto, las Mutualidades y Montepíos, según la Ley de 6 de diciembre de 1941, están exentos, conforme al artículo 10, de «las exacciones y arbitrios de las Corporaciones locales que graven los actos, contratos, documentos y patrimonios de las referidas entidades». Atendidos los "términos estrictos» de esta exención, las tasas no aparecen específicamente incluidas, lo que ha dado lugar a reiterada jurisprudencia del Tribunal Supremo (8) afirmando que «las exenciones tributarias de la legislación social no deben ser in-

(8) La última conocida es de 27 de abril de 1970 (Ar. 2.349). La sentencia de 31 de marzo de 1971 (Ar. 1.293), sin citar siquiera la posibilidad de aplicar los «términos estrictos", anula una liquidación de obras en virtud de recurso de reposición basado en haber obtenido la calificación de bonificable, no solicitada al interesar la licencia, después de su otorgamiento y antes de que la liquidación fuese firme. 
terpretadas con carácter meramente fiscal». Queda así matizada la prohibición de aplicar la llamada analogía extensiva, que tendrá lugar exclusivamente cuando se trate de leyes dictadas para obtener recursos económicos, pero no cuando la finalidad de la norma es de carácter social, apareciendo reafirmado el principio de que el fin de la Ley debe determinar su interpretación. Las contribuciones especiales nacieron y subsisten más que como fuente autónoma de la economía municipal como medio de reintegrar al erario municipal la cuantía del gasto en cuanto sea equivalente al incremento patrimonial, que de otra forma sería injustificado. El propio Tribunal Supremo, en el quinto Considerando de la sentencia de 23 de mayo de 1964 (Ar. 3.075), al aceptar la doctrina del Tribunal a quo afirmará que la imposición de contribuciones especiales «procede teóricamente en todo caso en que exista aumento de valor, sea o no determinable el experimentado por la propiedad del beneficiario, si bien, cuando tal aumento fuere susceptible de concreción, la contribución deberá absorberlo para que la realización del principio sobre el que se basa el instituto tributario sea completo".

Discriminada la parte de la inversión que corresponde a la utilidad general y la que supone un incremento de valor de ciertas propiedades, problema que en la práctica ofrece arduas dificultades, las contribuciones especiales habrán de absorber íntegramente el aumento de valor, y en cuanto no alcancen dicho límite se estará conculcando un principio elemental de justicia y el propósito indiscutible que motivó la creación de las contribuciones especiales.

El importe total del proyecto que las origina será la suma de los conceptos parciales a que se refiere el artículo 454 de la Ley de Régimen local, comprendiendo no sólo los «terrenos que las obras o instalaciones hubiesen de ocupar permanentemente», sino también los elementos accesorios a los terrenos, como es lo edificado; es decir, todos los gastos necesarios para la ejecución de la obra o instalación del servicio, con la limitación obligada de que el importe de las contribuciones especiales no podrán exceder del beneficio especial y el aumento de valor. El único derecho del deudor, aparte las garantías de procedimiento, es la observancia de este principio, y en tanto se respete, ninguna lesión se causará a su patrimonio, manteniéndose incólume no sólo el «sagrado derecho de la propiedad 
inmobiliaria", sino también el no menos sagrado del erario municipal, formado con las aportaciones mayoritarias de quienes carecen de bienes inmuebles.

\section{LAS CONTRIBUCIONES ESPECIALES, LA DESVIACION DE PODER Y LAS SUBVENCIONES DE MERA LIBERALIDAD}

La desviación de poder aparece en el Consejo de Estado francés en 1875, y se abre paso con mucha cautela en nuestra jurisprudencia a partir de 1920 , consagrándose en los artículos $4 .^{\circ}$ y $6 .^{\circ}$ del Reglamento de Servicios de las Corporaciones locales y de modo generalizado en el artículo 83 de la vigente Ley de la Jurisdicción contencioso-administrativa.

En cuanto vicio del acto administrativo, se define por la utilización de las potestades administrativas para fines distintos de los prescritos en el ordenamiento jurídico.

Es fácil advertir que si los ingresos municipales se han de destinar a atenciones generales del Municipio, en la medida que se apliquen «en favorecer especialmente intereses económicos particulares» se está incidiendo en la desviación de poder o malversación de las facultades de la Administración, como gráficamente ha dicho el Tribunal Supremo, figura próxima al «hurto de uso» tipificada en el Código penal.

No desvirtúa tal calificación la realización de una obra o servicio de la competencia municipal, pues si la plusvalía originada no se reintegra al erario municipal, y en la medida en que no se efectúe, los ingresos que por su origen y fin deben destinarse a atenciones generales se están aplicando a incrementar patrimonios particulares. Es intrascendente que entre los factores que determinan el incremento se hallen sólo terrenos o terrenos y edificios, siempre que se trate de gastos necesarios para ejecutar la obra que produce la plusvalía, ya que la desviación de poder en este caso sólo trata de evitar el enriquecimiento "torticero» que se puede producir en uno $u$ otro supuesto, manteniendo al propio tiempo la integridad del erario municipal con el destino que le es inherente, finalidades que, como se ha reiterado, justifican las contribuciones especiales.

El legislador ha adoptado medidas especiales para evitar tales distorsiones en la economía municipal, imponiendo las contribucio- 
nes especiales obligatoriamente con responsabilidad solidaria de la Corporación (arts. 130 de la Ley del Suelo y Ordenación urbana y $90^{\circ}$ de la Ley $48 / 1966$, de 28 de julio). No obstante, la obligatoriedad puede ser insuficiente si no se hace extensiva la imposición hasta el límite máximo que alcance el incremento de valor y el beneficio especial.

Desde otra perspectiva se puede llegar a la misma conclusión. El artículo 27 del Reglamento de Servicios prohibe las subvenciones de mera liberalidad y no parece discutible que tiene tal carácter la no absorción de las plusvalías originadas por la ejecución de obras o instalación de servicios. En cuanto se produzca, con tal motivo, un incremento de valor, en su total cuantía y sin exceder del desembolso municipal, deberá ser objeto de reintegro a través del mecanismo de las contribuciones especiales, pues al no tener el obligado al pago derecho alguno a obtener un lucro con la ejecución de la obra, ni tampoco título que le legitime para exigir una inversión en beneficio propio, el incremento de valor no reintegrado será subvención de mera liberalidad.

\section{EL EXTRAÑO REGIMEN DE SUBVENCIONES Y LA CUANTIA DE LAS CONTRIBUCIONES ESPECIALES}

La subvención -cadena de oro que cuanto más se incrementa mayor es su peso, como diría LACORDAIRE, refiriéndose a las que el Estado concedía a la Iglesia en Francia- puede revestir diversas modalidades, pero aquí sólo interesa la llamada de equilibrio (9), cuya finalidad es compensar la falta de medios suficientes en las Entidades locales para realizar los fines que les están atribuidos. La penuria de la Hacienda municipal para hacer frente a obras de infraestructura, cada día más costosas, tiene adecuada solución en el régimen de subvenciones del Estado, que si no deja de tener inconvenientes no es menos cierto que ofrece ventajas indiscutibles

(9) La subvención, como donación modal que es, no parece compatible con el carácter obligatorio que el artículo 106 de la Ley de Régimen local atribuye a la ayuda financiera que el Estado y la Provincia deben facilitar a los Municipios para la efectividad de los servicios mínimos obligatorios. Tampoco parece posible que determinado Municipio pueda exigir del Estado la ayuda financiera prevista, por lo que de hecho subsiste el carácter de la subvención. 
que no por ser generalmente silenciadas dejan de ser menos evidentes. En definitiva, la potestad de imposición originariamente radica en el Estado, que puede ampliar o restringir los límites de la concedida a los Entes locales por motivaciones cuyo análisis excede de la finalidad ahora perseguida.

Sin embargo, las subvenciones -frecuentemente encubiertas bajo la denominación de auxilios, quizá por comprender gastos accesorios intrascendentes, como redacción de proyectos- son verdaderos ingresos municipales, aunque circunstanciales y con finalidad específica, que el Estado está obligado a conceder para la efectividad de los servicios mínimos obligatorios atribuidos a la competencia municipal, según dispone el artículo 106 de la Ley de Régimen local.

El régimen de auxilios para saneamiento -abastecimiento de aguas y alcantarillado- se inicia por Real Decreto de 12 de enero de 1904, ampliándose sucesivamente por Reales Decretos de 23 de marzo de 1914, 9 de junio de 1925, y Decretos de 17 de mayo de 1940, 27 de julio de 1944, 17 de marzo de 1950, 1 de febrero de 1952, 10 de enero de 1958 y 31 de octubre de 1963.

El Ministerio de Obras Públicas, a través de la legislación citada, asume la ejecución de obras de competencia exclusiva de los Municipios que pierden este carácter, ya que, conforme al artículo 128 de la Ley de Régimen local, la obra municipal se tipifica, fundamentalmente, por ser ejecutada por el Ayuntamiento con sus propios fondos o "con auxilio de otras Entidades públicas o de particulares", modificando por simples Decretos el contenido de los artículos 106 y 128 de la Ley de Régimen local.

El problema tiene mucha mayor importancia que la derivada de la violación de la jerarquía normativa, pues si el Ayuntamiento subvenciona, régimen impuesto por los citados Decretos, las contribuciones especiales no pueden exceder de la cuantía de la subvención, artículo 454 de la Ley de Régimen local; pero si subvenciona el Estado, conforme dispone el artículo 106 de la Ley de Régimen local, la subvención no se descontará del costo de las obras, según establecen los artículos $50^{\circ}-2$ de la Ley de 24 de diciembre de 1962 y $90^{\circ}-4$ de la Ley de 28 de junio de 1966, que derogaron el artículo 454-3 de la Ley de Régimen local, derogación efectiva y vigente con independencia del criterio que deba prevalecer en cuanto a otros supuestos contemplados por dichas Leyes. 
El sistema establecido por la Ley de Régimen local pudiera ser más coherente al señalar como costo de las obras a efectos de contribuciones especiales, en todo caso, la cuantía del gasto que debe soportar la Hacienda municipal, pero la reforma introducida es más consecuente con el principio de justicia tributaria y, sobre todo, acepta tácitamente el verdadero alcance de la subvención, más exactamente aportación obligatoria, que no es otra que la vigorización circunstancial de la economía municipal para la ejecución de obra determinada de la competencia obligatoria del Municipio. No obstante, el fin de la reforma se ha frustrado y sólo se logrará cuando el Ministerio de Obras Públicas modifique el tan inveterado como antijurídico proceder de asumir la ejecución de obras municipales con subvención del Ayuntamiento.

El anómalo proceder de dicho Ministerio contrasta con el seguido por el de Educación y Ciencia para la construcción de edificios destinados a E. G. B., lo que fácilmente hace suponer las injustificadas motivaciones que dificultarán lạ resolución de un problema cuyo solo planteamiento debiera determinar la solución apropiada.

\section{COMPATIBILIDAD DE LAS CONTRIBUCIONES ESPECIALES Y LAS EXPROPIACIONES POR UTILIDAD PUBLICA}

La expropiación sólo puede ser utilizada por causa de utilidad pública o social. En su significación literal la utilidad pública se refiere a un interés generalizado, incompatible con intereses privados o concretos de determinadas personas, aunque siguiendo este criterio cuantitativo sería de difícil determinación cuando la obra o instalación deja de responder a intereses particulares para transformarse en obra de utilidad pública.

Sobre esta base parece evidente que si la expropiación ha de estar fundada en el interés general, habrán de ser los ingresos municipales los que hagan frente a su financiación, ya que no sería lícito que gastos de utilidad pública corrieran a cargo de determinadas personas, particularmente cuando las contribuciones especiales se fundan precisamente en una utilidad particular que no debe' afrontar la economía municipal. Aparece, por tanto, la expropiación por utilidad pública como incompatible con la exacción de contribuciones especiales. 
La oposición es puramente terminológica y se desvela con una ligera referencia a la finalidad que la Ley atribuye a esta primera exigencia de la expropiación: la declaración de utilidad pública.

La Ley de Expropiación forzosa, de 1879, preveía en su artículo 11 la aplicación de la misma con motivo de la ejecución de obras públicas, llevadas a efecto con arreglo a las prescripciones del Capítulo II de la Ley de Obras Públicas de 13 de abril de 1877. En una época de mínima intervención del Estado, la obra pública se definía, artículo $1 .^{\circ}$, como la de uso y aprovechamiento general, y las construcciones que se hallen a cargo del Estado, de las Provincias o de los pueblos.

El Estatuto Municipal rompe los estrechos moldes anteriores, y en el artículo 316 distingue las obras que los Ayuntamientos ejecuten en concepto de dueños de sus bienes patrimoniales de aquellas otras que con carácter de obras o servicios públicos municipales sirven directamente al cumplimiento de algunos de los fines atribuidos por precepto legal a la exclusiva competencia de los Ayuntamientos, las que éstos ejecuten por delegación del Estado o tengan a su cargo por precepto legal o las que subvencione el Municipio y ejecute el Estado o la Provincia.

La Ley de Régimen local sigue un criterio análogo, aunque más preciso, atribuyendo el carácter de obras municipales a las de nueva planta, reparación o entretenimiento que los Ayuntamientos ejecuten, con auxilios ajenos o sin ellos, "para la realización de servicios de la competencia municipal» (art. 128); añadiendo el artículo 143 que la aprobación de planes y proyectos de «toda clase de obras y servicios municipales implica la declaración de utilidad pública de las obras y la necesidad de ocupación de los terrenos y edificios que en ellos se determinen, a los efectos de expropiación forzosa».

Vinculada la declaración de utilidad pública a la realización de obras y servicios de la competencia municipal, ha perdido vigencia la significación etimológica, y por eso el proyecto de abastecimiento de aguas potables a media docena de propietarios se puede ejecutar con expropiación forzosa, no porque la obra sea de utilidad general —que no lo es-, sino porque es de competencia municipal, siendo, por tanto, inherente la utilidad pública a la competencia del Ayuntamiento. Cualquier obra de la competencia municipal es de utilidad pública a efectos de expropiación forzosa, sean muchos o pocos los beneficiarios. 
Confirma lo expuesto el propio texto del artículo 454-b) de la Ley de Régimen local, al disponer que se incluirá en el importe de las contribuciones especiales el "valor de los terrenos", que normalmente no se podrán adquirir si no es por el procedimiento de expropiación forzosa, con acta de acuerdo o justiprecio del Jurado. En cualquier caso, lo decisivo no será la causa de la expropiación, sino los efectos que produzca.

\section{CONCLUSIONES}

Las consideraciones precedentes han pretendido recordar la verdadera naturaleza de las contribuciones especiales y las consecuencias que la misma comporta, evitando cualquier posible confusionismo que podría abocar en interpretaciones desacertadas, al propio tiempo que se examinan problemas conexos cuya solución contribuiría a un eficaz saneamiento de la Hacienda municipal.

En apretada síntesis, las conclusiones a que se ha intentado llegar con su fundamentación, se podrían resumir así:

1. ${ }^{\mathrm{a}}$ Los impuestos suponen una detracción del patrimonio del obligado al pago y se destinan a cubrir los gastos generales del Estado o Ente público que los percibe. El respeto al derecho de propiedad y el superior control del poder legislativo postulan la existencia de una ley que no podrá ser interpretada ni extensiva ni analógicamente.

Las contribuciones especiales no pueden empobrecer el patrimonio del deudor; son el reintegro al erario municipal de un beneficio especial o aumento de valor; evitan el enriquecimiento sin causa y el que los rendimientos de los ingresos municipales, apartándose de su fin propio - desviación de poder-, sirvan para incrementar determinados patrimonios, cuyos titulares serían destinatarios de una subvención de mera liberalidad. Los gastos que origine la ejecución de la obra o instalación del servicio, en cuanto produzcan beneficio especial o aumento de valor, determinarán la cuantía de las contribuciones especiales. La expropiación de edificios como accesorios de los terrenos - interpretación extensiva-, puede dar lugar a exigir contribuciones especiales.

2. ${ }^{\text {a }}$ La obligatoriedad de imponer contribuciones especiales puede ser una medida insuficiente de protección al erario munici- 
pal, debiendo extenderse a exigirlas hasta el límite máximo del beneficio o aumento de valor.

3. ${ }^{a} \quad$ Los auxilios o subvenciones que el Ministerio de Obras Públicas concede para obras de saneamiento tienen la consideración legal de ingresos municipales extraordinarios con destino específico, y en ningún caso pueden justificar que obras típicamente municipales dejen de serlo en cuanto a su ejecución. El III Plan de Desarrollo, bajo el epígrafe "Descentralización y desconcentración», sienta el principio contrario, pues incluso las obras de competencia del Estado «deberán confiarse a los Entes territoriales cuando éstos lo soliciten y dispongan de los medios y capacidad gestora suficiente».

4. $\quad$ La expropiación por utilidad pública, atributo inherente a toda obra de la competencia municipal, es perfectamente compatible con la exacción de contribuciones especiales.

No se ha tenido la vana pretensión de lograr soluciones definitivas a los problemas que se dejan planteados, cuya trascendencia no es necesario poner de relieve, y que hasta ahora, en cuanto se nos alcanza, no han sido objeto de especial consideración ni por la doctrina ni por la jurisprudencia del Tribunal Supremo (10).

$\mathrm{Si}$ las sugerencias precedentes pueden servir de estímulo para un tratamiento más adecuado, o en trance de renovación de la legislación local son de alguna utilidad para el legislador, habrán cumplido la finalidad que las motiva; pues si sólo andando se hace camino, la huella queda trazada.

(10) Con posterioridad a la redacción de estas líneas, la sentencia del Tribunal Supremo de 2 de julio de 1973 sienta doctrina contraria a la aquí mantenida. 
REVL-1974, núm. 181. SUAREZ MORAN, FRANCISCO. LOS GASTOS QUE DETERMINAN LA CUANT... REVL-1974, núm. 181. SUAREZ MORAN, FRANCISCO. LOS GASTOS QUE DETERMINAN LA CUANT... 


\section{RESEÑA DE SENTENCIAS}

SUMARIO: I. BIENES DE LAS CORPORACIONES LOCALES: 1. ENAJENACIÓN EN SUBASTA: REVERSION POR INCUMPLIMIENTO DE LA OBLIGACIÓN DE CONSTRUIR. 2. REIVINDICACION ADMINISTRATIVA.-II. CONTRATACION ADMINISTRATIVA: CÓMPUTO DE PLAZOS.-III. EXPROPIACION FORZOSA: 1. DAÑOS Y PERJUICIOS: PRIVACIÓN DEL AGUA QUE LA FINCA VENfa DISFRUTANDO. 2. JUSTIPRECIO: APLICACIÓN DE VALORES DE LA LEY DEL SUElo. 3. JustIPRECIO: ARRENDATARIO DE VIVIENDA. 4. JUSTIPRECIO: CONFORMIDAD DE OTROS EXPROPIADOS. 5. JUSTIPRECIO: EXTINCIÓN DEL DERECH O ARRENDATICIO EN LOCAL DE NEGOCIO. 6. JUSTIPRECIO:

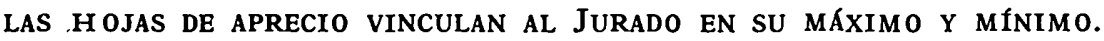
7. JUSTIPRECIO: TERRENO RÚSTICO CERCANO A LA URBE. 8. REVERSION: NO PROCEDE APLICAR EL 5 POR 100 DE AFECCIÓN. 9. REVERSION: MOMENTO AL QUE HA DE REFERIRSE LA VALORACIÓN: PREMIO DE AFECCIÓN. 10. SUPERFICIE EXPROPIABLE.-IV. FUNCIONARIOS: 1. FONDO DE INSPECCIÓN DE RENTAS Y EXACCIONES. 2. M. U. N P. A. L.: COMPETENCIA para declarar la invalidez. 3. Secretario de Comunidad de Tierra. V. HACIENDAS lOCALES: 1. ARbitrio de plusvalfa: Congregación religiosa. 2. Arbitrio de plusvalfa: deducción por mejoras. 3. ArBITRIO dE PLUSVALfA: DEDUCCIÓN DE DERECHOS REALES SATISFECHOS. 4. ARbitrio de plusvalfa: deducciones, PERfodo impositivo, escrituRa pública. 5. Arbitrio de plusvalfa: falta de aumento de valor. 6. ARbitrio de plusvalfa: fNDices, aprobación. 7. ARbitrio de plusVALfA: TERRENOS QUE TIENEN EL CONCEPTO DE SOLAR. 8. ARBITRIO SOBRE SOLARES SIN EDIFICAR: EXENCIÓN DE TERRENOS SOMETIDOS A PLAN DE REPARCELACIÓN OBLIGATORIA. 9. CONTRIBUCIONES ESPECIALES: EXPEDIENTE ÚNICO PARA DIVERSAS OBRAS DE REPAVIMENTACIÓN. 10. CONTRIBUCIONES ESPECIALES: NO ES PRECISA LA APROBACIÓN DEL EXPEDIENTE POR EL DELEgado DE HaCIENDA. 11. DERECH OS Y TASAS: RECOGIDA DE BaSURAS, EXENCIÓN BANCO DE ESPAÑa. 12. LIQUIDACIONES PROVISIONALES: RECURSOS CONTRA LAS MISMAS. 13. ORDENANZAS FISCALES: FALTA DE BASE PARA SU IMPUGNACIÓN.-VI. JURISDICCION CONTENCIOSO-ADMINISTrativa: 1. Previo pago: aVal bancario. 2. Suspensión de acuerdo MUNICIPAL: IMPROCEDENCIA.-VII. POLICIA MUNICIPAL: 1. AUTOTAXis: aNUlación de licencia. 2. Fiscalfa de la Vivienda: lfmites de COMPETENCIA CON El AyUNTAMIENTO. 3. Edificios RUinosos: construc- 
CIONES FUERA DE ALINEACIÓN. 4. EDIFICIOS RUINOSOS: OBRAS DE CONSERVACIÓN.-VIII. PROCEDIMIENTO ADMINISTRATIVO: 1. INFRACCIÓN DE LA NORMa RITUARIA. 2. RECLAMACIÓN ECONÓMICO-ADMINISTRATIVA: FalTa dE LEgITIMACIÓN aCTIVa dE UN AYUNTAMIENTO.-IX. RESPONSABILIDAD ADMINISTRATIVA: PROFUNDOS BACHES NO SEÑALIZADOS EN CARRETERA PROVINCIAL. - X. SOLARES E INMUEBLES DE EDIFICACION FORZOSA: 1. COMPETENCIA PARA ACORDAR LA INCLUSIÓN EN EL REgISTRO. 2. EDIFICACIONES INADECUADAS.-XI. URBANISMO: 1. Arbitrio sobre aumento de edificabilidad. 2. Nulidad de lífencïa de CONSTRUCCIÓN EN ZONA VERDE. 3. TERRENO NO EDIFICABLE: TRANSCURSO DEL PLAZO DE DIEZ AÑOS SIN EXPROPIAR.-XII. ZONA MARITIMO-TERRESTRE: 1. Deslinde. 2. Deslinde: otra SENTENCIA.

\section{BIENES DE LAS CORPORACIONES LOCALES}

1. ENAJENACIÓN EN SUBASTA: REVERSIÓN POR INCUMPLIMIENTO DE LA OBLIGACIÓN DE CONSTRUIR

Considerando: Que, siendo la Administración uno de los sujetos contratantes, teniendo el contrato por objeto un bien cuya titularidad ostentaba el expresado Ayuntamiento y persiguiendo fines de interés público, la naturaleza del contrato inicialmente celebrado por el Ayuntamiento de Vivero es evidentemente administrativa, según la doctrina que el Tribunal Supremo ha venido sosteniendo en sentencias como las de 26 de junio de 1965, 4 de mayo de 1968, 29 de abril de 1971 y especialmente en las de 21 de abril de 1970 y 15 de febrero de 1971, expresiva la primera de que el contrato administrativo no sólo tiene por objeto la contratación de obras y servicios, sino también de bienes, según establece la disposición adicional primera del Reglamento de Contratación de las Corporaciones Locales, en concordancia con lo dispuesto en el artículo $4 .^{\circ}$, número 1 , apartado a), del Regalmento de Bienes, y señalándose en la segunda que la expresión "obras y servicios» debe ser objeto de una interpretación amplia, similar a la de interés público o general, siendo por ello desestimables las alegaciones que con fundamento en la naturaleza civil del contrato inicialmente celebrado por el Ayuntamiento de Vivero, se hacen en la primera de las consideraciones jurídicas de la demanda.

ConsIDERANDO: Que reconociéndose en el expediente administrativo por el Ayuntamiento de Vivero a don Juan E. G. como pro- 
pietario de la parcela núm. 32 de la ciudad veraniega de Covas, las cuestiones a resolver en el presente pleito se reducen a determinar si el señor E. se encontraba obligado a la edificación de la parcela en los plazos fijados y, en caso afirmativo, si el incumplimiento de tal obligación habría de producir jurídicamente la reversión del solar al patrimonio municipal, conforme ha sido acordado por el Ayuntamiento, siendo preciso llegar a la conclusión, atendidos los antecedentes de hecho que se recogen en el primer considerando de esta sentencia, de existir por parte del señor $E$. la obligación de edificar la mencionada parcela, al consentir y no recurrir los Acuerdos municipales en que se le requiere para ello, en fechas posteriores al 29 de octubre de 1962, en que inscribió su adquisición en el Registro de la Propiedad, advirtiéndole también la Corporación municipal de una manera expresa en sus repetidos Acuerdos de los años 1963, 1964 y 1965, que en ningún momento fueron recurridos, de la reversión del solar al patrimonio municipal en caso de incumplimiento de la obligación de edificar, lo que finalmente se lleva a efecto -en adecuada aplicación de los artículos $6 .^{\circ}$ del pliego de condiciones y $4 .^{\circ} 5 .^{\circ}$ y $6 .^{\circ}$ de la Ordenanza de la ciudad veraniega de Covas - en el Acuerdo adoptado el 27 de abril de 1971, que es confirmado en todas sus partes el 8 de junio de 1971, al desestimar el recurso de reposición interpuesto contra el mismo. (Sentencia de 2 de marzo de 1973, Ar. 971).

\section{REIVINDICACIÓN ADMINISTRATIVA}

CoNSIDERANDo: Que igualmente es recusable la tercera y última de las alegaciones efectuadas, por cuanto lo que en el caso es necesario acreditar es la mera tenencia posesoria -art. 55 , párr. $3 .^{\circ}$, del Reglamento de Bienes-y no, cual por las demandantes se pretende, todos y cada uno de los requisitos que la Ley y la doctrina jurisprudencial establecen para la reivindicación; y como la posesión de los terrenos recuperados por la Administración municipal es reconocida por las propias demandantes, apareciendo los actos de éstas al construir la verja como actos realizados al margen del conocimiento del poseedor, que no obstan a la posesión como derecho -art. 444 del Código civil-, presumiéndose una situación de posesión continuada con arreglo a lo dispuesto en el artículo 459 del mismo texto legal, es obvio debe estarse a la repulsa manifestada, 
al darse en el caso las bases fáctico-jurídicas que permiten la acción municipal actuada. (Sentencia de 7 de marzo de 1973, Aranzadi 1.024).

\section{CONTRATACION ADMINISTRATIVA}

\section{Cómputo DE PLAZOS}

CONSIDERANDO: Que para conocer los dias inhábiles a los efectos administrativos no cabe acudir al "calendario» que anualmente aprueba el Gobierno y se publica a impulso del Ministerio de Trabajo, a tenor de lo que dispone el artículo $3 .^{\circ}$ del Decreto de 7 de febrero de 1958, porque estos calendarios, como es el aprobado para el año 1967 por la Orden de 23 de diciembre de 1966, rectificada en 28 de febrero siguiente, señalan las "fiestas locales y consuetudinarias» a los efectos de las relaciones laborales, pero no con eficacia para atender qué indicados días son feriados o inhábiles para las actuaciones administrativas, pues por dias inhábiles deben entenderse, según el artículo 282 del Reglamento de Organización, Funcionamiento y Régimen Jurídico de las Corporaciones Locales -según el art. 60 de la Ley de Procedimiento administrativo--; los que han sido fijados a los efectos administrativos en las disposiciones a que explícitamente se remiten aquellos preceptos, esto es, el Decreto de 23 de diciembre de 1957 -y sus posteriores ampliaciones, como las de 10 de enero y 24 de septiembre de 1958-, disposiciones que no pueden alterarse por una práctica en contrario; $y$ es en estas disposiciones donde, en lo que atañe a las festividades religiosas locales, que es lo que interesa en este recurso, se requiere -según el artículo 2.0- que tales festividades sean de "precepto", calificación que no es la del dia de San Esteban, pues aunque una arraigada tradición hace que este día en Cataluña se celebre como "festivo" y así lo es a los efectos laborales, hasta el punto de que en todos los órdenes la costumbre - sin eficiencia, no obstante, para crear un día inhábil - ha impuesto la abstención de toda actividad que no sea la propia de un día de fiesta, es lo cierto que no es día de precepto desde que el Decreto Pontificio de S. S. Pío XII, mandado observar y publicado por el Real Decreto de 26 de junio de 1967, suprimió la canónica obligación de oír Misa indicado día; y si no es día de precepto, la regla del artículo $2 .^{\circ}$ del 
Decreto de 1957 es bien clara a los fines de inferir que es hábil para las actuaciones administrativas. (Sentencia de 23 de marzo de 1973, Ar. 1.292).

\section{EXPROPIACION FORZOSA}

1. DAÑos Y PERJUICIOS: PRIVACIÓN DEL AGUA QUE LA FINCA VENÍa DISFRUTANDO

Al no ser los demandantes titulares de ningún derecho que haya sido directamente expropiado de modo permanente por la Administración, no pueden exigir se les tenga como parte interesada en el expediente expropiatorio de las fincas que se expropian con motivo de la construcción de la carretera de acceso a Málaga, y en su virtud, la Administración no tenía la obligación de citarles en el expediente, al no darse los supuestos precisos para ello, porque no se encuentran comprendidos en los supuestos que para el procedimiento ordinario se contemplan por la Ley que regula este instituto, pues no están incluidos en los que relaciona el artículo $30^{\circ}$ de la Ley de Expropiación forzosa; por tanto, la primera petición de su demanda ha de ser desestimada.

Que en cambio su petición subsidiaria, que en todo caso habría de examinar de oficio, por tratarse de una cuestión de orden público, tiene a su favor el que al estar legitimados para reclamar la indemnización de los daños y perjuicios que les haya causado el actuar de la Administración, al realizar la obra de construcción de la carretera de acceso a' Málaga, su petición debió : ser tramitada conforme se dispone para estos casos, examinando la Jefatura Regional de Carreteras su propia competencia y actuando en consecuencia, o siguiendo las normas a que se remite el artículo 121 de la Ley de Expropiación forzosa, o remitiendo la solicitud a quien creyese era competente para resolverlo, como ordena el artículo $8 .^{\circ}-2$ de la Ley de Procedimiento administrativo, pero no rechazar tal pretensión dentro del expediente de expropiación, en el que no eran parte los reclamantes, y cuando de sus escritos iniciales resultaba claramente que no pretendían un justiprecio por ningún bien del que se les privaba, sino una indemnización por los perjuicios que les había ocasionado con motivo de la actuación administrativa en la construcción de una carretera. (Sentencia de 29 de marzo de 1973, Ar. 1.391). 


\section{Justiprecio: aplicación DE valores de la LeY DEL Suelo}

CONSIDERANDO: Que la jurisprudencia de esta Sala (sentencias de 14 de febrero de 1968, 2 de noviembre de 1970, 11 de noviembre de 1971 , etc.) ha declarado reiteradamente que el ámbito propio de las expropiaciones urbanísticas es el de las actividades para desarrollar y ejecutar planes de ordenación urbana o el Plan Nacional de la Vivienda, de modo que cuando una obra pública no obedezca a esta finalidad es inaplicable, para valorar los terrenos expropiados, la Ley del Suelo, y ha de serlo la Ley de Expropiación forzosa, y por ello, dentro del expediente expropiatorio, se exige que se pruebe no sólo la existencia de un plan de urbanismo, sino que éste sea el motivo determinante de la obra en cuestión, sin que baste que la Administración invoque que lleva a cabo su actividad expropiatoria para una finalidad urbanística, sino que se precisa que para ejecutar el plan de ordenación se realice aquélla, ya que cuando se trata de construir centros de servicios públicos, como en este caso las escuelas que podrían incluso edificarse en terreno rústico no planificado, con arreglo a lo dispuesto en el artículo 69 de la Ley del Suelo, hay que demostrar que su construcción obedece a la ordenación urbanística de un sector y no a otras finalidades, como la de proporcionar centros de esta clase a la localidad, que no serían urbanísticas, sino de satisfacción de necesidades de la población, y en el caso actual, la expropiación forzosa se ha comprendido para dotación de escuelas, y aunque se dice están previstas en el plan de ordenación urbana, no se han aportado, ni el plan que se ejecute, ni en antecedente alguno, que permita deducir que se ha expropiado exclusivamente para efectuar una ordenación urbanística. (Sentencia de 12 de marzo de 1973, Ar. 1.057).

\section{JUSTIPRECIO: ARRENDATARIO DE VIVIENDA}

ConsIDERANDo: Que tanto la Ley de Arrendamientos urbanos, en su artículo 114, al contemplar la expropiación forzosa del inmueble como causa de resolución de los arrendamientos en él existentes, disponiendo la indemnización de los arrendatarios, como el artículo 44 del Reglamento de la Ley de Expropiación forzosa al desarrollar el 44 de la Ley de Expropiación, permitiendo en cual- 
quier hipótesis de indemnización prevista a favor de arrendatarios de fincas expropiadas, la aplicación del artículo 43 de la Ley, tiende a que los titulares de derechos arrendaticios obtengan como indemnización el precio real y verdadero de los perjuicios sufridos al cesar en el arrendamiento de tales supuestos, por lo que de su interpretación sistemática se deduce que al respecto señalan módulos que, como han declarado las sentencias de esta Sala de 12 de mayo de 1971 y 14 de junio del mismo año, no son inalterables, sino que permiten a los inquilinos obtener mayores cantidades que el límite de seis meses de mensualidades de la renta que venían satisfaciendo, siempre que se justifiquen mayores perjuicios, entre los que caben todos los que el Jurado de Expropiación forzosa ha recogido, por lo que al señalar la indemnización no sólo en la cuantía de las mensualidades de renta establecidas en la Ley de Arrendamientos urbanos, sino añadiendo otras cantidades por perjuicios a consecuencia del desalojo de la finca, ha hecho uso y aplicación adecuada del artículo 44 de la Ley y del mismo ordinal del Reglamento de Expropiación forzosa, en relación con el 43 de la Ley de 16 de diciembre de 1954 y no ha incurrido en error material ni de procedimiento valorativo, sino en recta interpretación del principio de que el arrendatario pueda adquirir local de iguales condiciones al que ocupaba con anterioridad a la expropiación, como reconoce la jurisprudencia (sentencias de 16 de junio de 1961 y 15 de enero de 1963). (Sentencia de 24 de febrero de 1973, Ar. 545).

\section{JUSTIPRECIO: CONFORMIDAD DE OTROS EXPROPIADOS}

Considerando: Que la circunstancia de que algunos propietarios afectados por la susodicha expropiación hayan aceptado justiprecios inferiores, no puede perjudicar al interesado en este pleito, ya que de lo contrario actos de disposición de un tercero podrían influir, sin razón que lo justificase, en la esfera patrimonial ajena; teniendo declarado la jurisprudencia a este respecto que la conducta de otros expropiados nada presupone en relación con el real y verdadero valor de los bienes objeto de la transferencia coactiva. Que también ha de tenerse en cuenta que, en orden a los casos de justiprecio aducidos por el Ayuntamiento como antecedente, no demostró el último, debidamente, que guarden la necesaria identidad con el que ahora es objeto de controversia. (Sentencia de 19 de febrero de 1973, Ar. 499, y sentencia de 7 de marzo de 1973, Ar. 950). 
5. JUSTIPRECIO: EXTINCIÓN DEL DERECH O ARRENDATICIO EN LOCAL DE NEGOCIO

Considerando: Que al interpretar la jurisprudencia del Tribunal Supremo los criterios valorativos a los que compendiosamente se remite el artículo 44 de la Ley de Expropiación forzosa y que, en síntesis, son los descritos en los artículos $73-3$ y 114-9 de la Ley de Arrendamientos urbanos de 24 de diciembre de 1964, señala como pautas a tener en cuenta: el precio medio de traspaso para la obtención de otro local de las mismas características o, en defecto de las posibilidades para determinarlo, la capitalización de la diferencia de rentas, siendo, por regla general, ambos criterios incompatibles entre sí (sentencias de 29 de septiembre de 1967, 26 de junio de 1968, 9 de octubre de 1969, 2 de noviembre de 1970 y 21 de mayo de 1971, entre otras), aun cuando esta incompatibilidad admite matices muy peculiares de apreciación ad exemplum (sentencia de 31 de mayo de 1971 y las que en ella se citan); los gastos de traslado y de nueva instalación y los perjuicios de todo tipo producidos por lucro cesante -incluso por pérdida de la clientela o por su disminución- durante dicho traslado (sentencias de 7 y 21 de febrero de 1967, 8 de marzo de 1969 y 24 de abril de 1971). (Sentencia de 31 de marzo de 1973, Ar. 1.397).

\section{JUSTIPRECIO: LAS HOJAS DE APRECIO VINCULAN AL JURADO EN SU MÁXIMO Y MÍNIMO}

Considerando: Que el artículo 34 de la Ley de Expropiación forzosa de 16 de diciembre de 1954 dispone que "el Jurado de Expropiación, a la vista de las hojas de aprecio formuladas por los propietarios y por la Administración, decidirá ejecutoriamente sobre el justo precio que corresponda a los bienes o derechos objeto de la expropiación", precepto que consagra -como tiene declarado la doctrina de esta Sala, consignada en las sentencias de 3 de diciembre de 1966 y 7 de octubre de 1970, entre otras- la eficacia vinculante para las partes y para el Jurado de las hojas de aprecio formuladas por aquéllas, pues — como declara la primera de las citadas sentencias- "no es lícito una reforma oficiosa que quebrante los límites impuestos por las hojas de aprecio", por lo que es 
manifiesto que en el presente caso la alusión por primera vez al pozo y alberca por los propietarios expropiados en su escrito de interposición de recurso de reposición contra el acuerdo del Jurado de Expropiación, atribuyéndoles una valoración de 300.000 pesetas, es tan extemporánea como inoperante, por no estar respaldado por prueba alguna, ya que, como antes se ha destacado, el perito arquitecto no alude a los repetidos pozo y alberca en el informe que se acompañó a la hoja de aprecio de los propietarios de los bienes expropiados. (Sentencia de 26 de marzo de 1973, Aranzadi 1.308 ).

\section{JUSTIPRECIO: TERRENO RÚSTICO CERCANO A LA URBE}

ConSIDERANDO: Que por mucho que 'se esfuerce tal parte recurrente para otorgar a la finca de autos el carácter de solar, éste no puede ser declarado por el mismo, en cuanto que la finca que nos ocupa es esencialmente rústica, como lo denota su relativa extensión, su ubicación y emplazamiento, la ausencia de confinamientos con calles o vías públicas, la alusión que en su descripción se hace con camino de servidumbre y, en especial, con lo observado por el Jurado en la correspondiente diligencia de inspección ocular - y que la Sala corroboró en la por ella llevada al lugar de la expropiación, con la trascendencia que a la misma le da el Tribunal Supremo en su sentencia de 19 de febrero de 1969-, calificación que no impidió a la Sala, y anteriormente al Jurado, para tener en cuenta un factor importantísimo en su valoración, la proximidad a núcleo urbano, lo que impulsó a dicho organismo a prescindir de los criterios señalados en la Ley de Expropiación forzosa para fines exclusivamente rústicos y remitirse, para justipreciar el bien de autos, al criterio más plausible y justo del artículo 43 del texto legal de la expropiación. (Sentencia de 12 de marzo de 1973, Aranzadi 1.055 ).

\section{REVERSIÓN: NO PROCEDE APLICAR EL 5 POR 100 DE AFECCIÓN}

ConsIDERANDo: Que el premio de afección que al expropiado concede el artículo 47 de la Ley de Expropiación forzosa, de 16 de diciembre de $: 954$, tiene, conforme a la jurisprudencia de este Tri- 
bunal Supremo (sentencias de 22 de noviembre de 1962 y 11 de mayo de 1964, entre otras), una naturaleza compensatoria del aspecto meramente subjetivo de la expropiación; es decir, del aprecio afectivo del propietario que, por razones de utilidad pública, se ve privado de su derecho, obedeciendo a razón de carácter espiritualista y no meramente económico, y por ello la propia doctrina de la Sala ha sostenido reiteradamente en las sentencias citadas en los «Vistos» que el premio de afección no alcanza a las indemnizaciones que con independencia del justiprecio del bien o derecho expropiado puedan derivarse de la expropiación. (Sentencia de 5 de marzo de 1973, Ar. 946).

9. REVERSIÓN: MOMENTO AL QUE HA DE REFERIRSE LA VALORACIÓN: PREMIO DE AFECCIÓN

CONSIDERANDO: Que para cumplir lo ordenado en la sentencia de 18 de abril de 1967, de conformidad con el artículo 54 de la Ley de Expropiación forzosa, ha de practicarse la valoración de los terrenos objeto de la recuperación atendiendo a la situación de los mismos en el momento en que se solicitó.

Considerando: Que la adición del 5 por 100 como premio de afección que el acuerdo del Jurado efectúa y confirma la sentencia apelada sobre el precio de tasación es totalmente improcedente, puesto que el artículo 47 de la Ley de Expropiación forzosa ordena se abone tal premio al expropiado, pero no al expropiante o beneficiario de la expropiación, faltando además el fundamento de tal premio, que se concede por la privación forzosa de los bienes en aras de la utilidad pública, lo que no sucede en los casos de reversión, cuyo motivo es el incumplimiento por parte del beneficiario de la expropiación de la finalidad que justificó la transferencia del dominio, incumplimiento que no puede dar lugar a premio de ninguna clase. (Sentencia de 16 de febrero de 1973, Ar. 492).

\section{SUPERFICIE EXPROPIABLE}

ConsIDERANDo: Que si bien en el acta previa a la ocupación, fechada en Candás el 2 de abril de 1968, se hizo constar como tal la de 3.082 metros cuadrados por la Administración, dicha mensura no 
fue aceptada por la propiedad en ningún momento, ni en la referida diligencia administrativa, ni en la hoja de aprecio, ni en el recurso contencioso ni en éste mismo; los acuerdos impugnados se limitan a especificar el justo precio, en la cantidad señalada en los mismos, reduciéndose a multiplicar la superficie fijada por la Administración expropiante por la cantidad de 500 ptas., que el Jurado estima ser el verdadero valor por metro cuadrado, proceder éste no ajustado al ordenamiento jurídico, ya que, como dice la sentencia de la Sala 5. ${ }^{a}$ de 19 de abril del presente año, al ser uno de los principios fundamentales de la Ley de 16 de diciembre de 1954 que la Administración concrete exactamente los bienes que han de ser expropiados, individualizándolos materialmente, las consecuencias de una imprecisión de este tipo han de ponerse a cargo de la entidad expropiante, y por ello la jurisprudencia de esta Sala (sentencias de 6 de mayo de 1954, 5 y 6 de noviembre de 1962) ha declarado que "la extensión superficial ha de quedar perfectamente determinada en el expediente expropiatorio, sin que el Jurado provincial de Expropiación forzosa pueda eludir ese extremo; por lo que el citado organismo debió especificar la superficie sobre la que realmente recaía la expropiación. (Sentencia de 29 de marzo de 1973, Ar. 1.393).

\section{FUNCIONARIOS}

\section{FONDO DE INSPECCIÓN DE RENTAS Y EXACCIONES}

No puede pretenderse la participación correspondiente al cargo de Jefe de Inspección de Rentas y Exacciones durante el tiempo que el cargo fue ejercido por otro funcionario nombrado por la Corporación, y cuyo nombramiento fue después anulado por sentencia firme, defiriéndolo al actor. (Sentencia de 28 de marzo de 1973, Ar. 1.313).

\section{M. U. N. P. A. L.: COMPETENCIA PARA DECLARAR LA INVALIDEZ}

CONSIDERANDO: Que si bien es cierto que, conforme se razona en la resolución del Ministerio de la Gobernación, que en este recurso se impugna y a tenor del artículo 41 de los Estatutos de la 
Mutualidad Nacional de Previsión de la Administración Local, corresponde a este organismo la competencia exclusiva para apreciar y calificar la invalidez de los asegurados, sin embargo, dicho precepto no puede interpretarse en el sentido de que pueda quedar al arbitrio de los órganos rectores de la Mutualidad la calificación de la invalidez de los funcionarios y su derecho a pensión, es decir, en definitiva, que aquéllos puedan jubilarse o no por imposibilidad física, ni siquiera que se trate de facultades discrecionales, sino que la única hermenéutica que del texto estatutario puede aceptarse es que la Mutualidad deberá tener en cuenta, apreciándolos conjuntamente, los certificados facultativos y los informes de la Corporación en que el funcionario preste sus servicios, pues no es posible desconocer que es a la que mejor puede constarle su eficiencia o inutilidad en la prestación de aquéllos, ni tampoco puede admitirse que ante un procedimiento desestimatorio del organismo mutual tenga la Corporación local que mantener en activo a un funcionario cuando la enfermedad que padece le obliga a frecuentes bajas o licencias, originando los consiguientes perjuicios en el cumplimiento de los servicios y en los intereses de la Corporación. (Sentencia de 5 de febrero de 1973, Ar. 420).

\section{Secretario de Comunidad de Tierra}

ConsIDERANDo: Que la pretensión del recurrente de que se anule la resolución de la Dirección General de Administración Local, confirmada por el Ministerio de la Gobernación, que dispuso su cese en el cargo de Secretario de la Comunidad del Real Señorío de Molina y su Tierra, y se le confirme en el desempeño del mismo, ha de examinarse en relación con las disposiciones de la Ley de Régimen local y sus Reglamentos que regulan el gobierno de tales Comunidades, y los hechos acreditados en el expediente administrativo. Al disponer el artículo 40 de la Ley de Régimen local que se respetarán las antiguas Comunidades de Tierra, dentro de la seccción que regula las Mancomunidades, permite su continuación dentro de la normativa actual, reguladas por sus normas consuetudinarias, como expresamente dispone el artículo 101 del Reglamento de Organización, Funcionamiento y Régimen Jurídico de las Entidades Locales, e igualmente el artículo 69 del Reglamento de Población y Demarcación Territorial de las mismas Entidades; por 
tanto, la Comunidad del Real Señorío de Molina y su Tierra ha venido rigiéndose por sus normas consuetudinarias o tradicionales, sin adaptarlas a las disposiciones sobre Administración local hasta sus nuevos Estatutos, aprobados por la Dirección General de Administración Local en 16 de diciembre de 1968, que ha supuesto la petición del recurrente y la resolución impugnada.

Considerando: Que tanto el Reglamento de Funcionarios de Administración Local, en sus artículos 20, 21 y 193, para el nombramiento de Secretarios, como el artículo 71 del Reglamento de Población y Demarcación Territorial para los Secretarios de las Comunidades de Tierra, disponen que se efectuará por el Director General de Administración Local mediante concurso y entre los funcionarios que pertenezcan al Cuerpo Nacional, nombramiento que no se ha conferido al recurrente con estos requisitos, puesto que fue designado en el año de 1957 (vigente ya la Ley de Régimen local y sus Reglamentos) por la Junta de Apoderados de la Comunidad; por lo que para tener el carácter de funicionario en propiedad de la Administración local en dicho cargo le falta el requisito de nombramiento legal que exige el artículo $10^{\circ}$ del Reglamento de Funcionarios de Administración Local, y su relación de servicio ha de ser de otra naturaleza. (Sentencia de 17 de febrero de 1973, Ar. 494).

\section{HACIENDAS LOCALES}

\section{Arbitrio de plusvalfa: Congregación Religiosa}

Considerando: Que esta Sala, en sus sentencias de 7 de julio de 1969 y 13 de marzo de 1970, relativas también a las Comunidades de Religiosas que vendieron las casas que, respectivamente, ocupaban en calles céntricas de una ciudad para construir otras en las afueras, declaró improcedente la exención del arbitrio sobre el incremento del valor de los terrenos, que habían reconocido las sentencias de primera instancia, por tratarse de supuestos de transmisiones onerosas, en los que el artículo 520, apartado 2, de la Ley de Régimen local manda someter al gravamen, como si la exención periódicamente disfrutada bajo la modalidad de tasa de equivalencia no hubiera existido, por lo que ahora tampoco es proce- 
dente acceder a la exención, ni aun siquiera con el alcance de reducir la duración del período impositivo, fijando el momento inicial en el de la terminación del último período decenal tomado en cuenta para las Sociedades, Asociaciones, Corporaciones y demás Entidades; porque, producida la desafectación de los bienes, del destino que determinaba la exención del arbitrio, en la forma de tasa de equivalencia, desde el momento que no se admite aquí la subrogación real, el período impositivo viene ya determinado por el párrafo $2 .^{\circ}$ del artículo 510 de la Ley de Régimen local, puesto que el artículo 520-2 tiene como inexistente la exención anterior y sería contrariar este precepto legal el tener en cuenta la exención hasta el momento en que las demás Entidades pagaron la última tasa periódica; sin que, por otra parte, proceda acudir directamente al Concordato, en una materia en que lo pactado entre las dos Altas Partes que en él intervinieron ha tenido reflejo en una Ley, como es la de Régimen local, cuya aplicación inmediata no plantea problema doctrinal alguno, bien distinto de lo que sucede con los Tratados Internacionales. (Sentencia de 2 de marzo de 1973, Ar. 991).

\section{ARBITRIO DE PLUSVALfa: DEDUCCIÓN POR MEJORAS}

Considerando: Que el objeto del arbitrio de plusvalía es el incremento que en un período de tiempo experimenta el valor de todos los terrenos sitos en el término municipal del Ayuntamiento de la imposición, con la única excepción de aquellos dedicados a explotaciones agrícolas, forestales, ganaderas o mineras y que no tengan la consideración legal de solares, conforme señala el artículo 510 de la Ley municipal, y el período tributario está constituido por los dos momentos que han de servir para obtener la diferencia del aumento de valor, es decir, valor inicial y valor final; por tanto, la base imponible está constituida por la diferencia en más entre el valor corriente en venta de los terrenos en la fecha final del período impositivo y el mismo valor al comienzo de tal período y de esta base el artículo 512-1 a) dispone que se deducirá el valor de las mejoras permanentes realizadas en el inmueble durante el período de imposición y subsistentes al final del mismo, es decir, que las mejoras han de referirse al suelo y no pueden acogerse las que tengan por objeto aumentar el valor de las edificaciones existentes 
en dicho terreno; el arbitrio fue establecido tan sólo sobre el incremento del valor del terreno, sin inclusión del valor de los edificios; las obras realizadas en éstos no generan, por tanto, desgravación, resultando de lo que se deja expuesto, como primera consecuencia, que, dada la generalidad de este arbitrio, que comprende a todos los terrenos del término municipial y el principio de igualdad de todos los contribuyentes ante la norma fiscal, que aquel que pretenda una reducción por mejoras permanentes realizadas en el terreno tiene sobre él la carga de la prueba; las mejoras tienen que estar probadas; las deducciones no se producen ope legis, y la segunda consecuencia implícita a la propia naturaleza que tienen en el aspecto fiscal el valor de esas mejoras que son deducciones legales establecidas para rectificar la base valorativa, es que se haya tenido en cuenta su valor por la Corporación al fijar los índices trienales en la zona correspondiente a dichos terrenos; por tanto, en todos los casos en que la Corporación no haya reconocido o discuta este hecho, el recurrente tiene que probar no sólo que existieron las mejoras, sino también que el valor de éstas se tuvo en cuenta al fijar los índices municipales, porque el procedimiento que señala la Ley para determinar la base del arbitrio no es otro más que el de la fijación de los índices trienales; por ellos se obtiene el incremento gravado. El artículo 512 dispone que las deducciones han de verificarse al final del período de imposición, por lo que sólo se podría deducir del incremento gravado el valor de las mejoras, que es una operación a posterius, si la plusvalía experimentada por ellas se computó a prius en los índices para obtener el valor en venta de los terrenos; pero si no se tuvo en cuenta el valor de las mejoras, la deducción es improcedente, como acertadamente se razona en la sentencia apelada, siguiendo el criterio de la sentencia de esta Sala de 7 abril de 1969, dictada en un caso análogo en el que también se entró a resolver el contenido y alcance del apartado a) del número 1 del artículo 512 de la Ley de Régimen local, puesto que en las de fecha posterior, que se citan por la apelante, o no entraron a resolver esta cuestión, específica y concreta, referente a si el valor de las mejoras se había computado al fijar los indices, o se refieren a casos en que la Corporación no discutió si habían sido tenidos en cuenta por ella al confeccionar los índices, lo que relevaba de prueba al actor sobre este tema, porque lo que se discutía era si existían mejoras permanentes en la finca. (Sentencia de 23 de febrero de 1973, Ar. 731). 


\section{ARbitrio de plusvalfa: deducción de derechos reales SATISFECHOS}

ConsIDERANDo: Que el artículo 511-3 de la Ley de Régimen local faculta a los Ayuntamientos para fijar el valor inicial del período impositivo tomándolos del consignado en las escrituras $\mathrm{y}$, en su defecto, los que resulten en valoraciones oficiales practicadas en aquella época y por ello estimando el legislador que en tales supuestos los precios de compra consignados en esos títulos frecuentemente son más bajos que los corrientes en el mercado inmobiliario es la razón por la que en el 512-2 dispone que siempre que la estimación del valor corriente en venta se base en algún precio, se sumarán a dicho precio cuantos gastos accesorios hubieran pesado sobre el adquirente por razón de la adquisición, pero tal precepto no es de aplicación al caso que aquí se contempla, pues, como ya se deja indicado, la propia parte recurrente y apelante ha reconocido expresamente en sus escritos fundamentales que el Ayuntamiento de Galdácano practicó las liquidaciones aplicando como valor inicial y final las que figuraban en los correspondientes índices trienales, por lo que no procede sumar o añadir al valor inicial el importe de los derechos reales satisfechos por el anterior adquirente de los terrenos aportados a la sociedad recurrente. (Sentencia de 23 de febrero de 1973, Ar. 731).

\section{ARbitrio de plusvalfa: DEDUCCIONES, PERfodo impositivo, ESCRITURA PÚBLICA}

Considerando: Que la posibilidad de divergencia entre el nacimiento de la transmisión de un determinado fundo y su formulación escrita o notarial surge del hecho de que en nuestro Derecho civil la propiedad se adquiere, aparte de por otros títulos, "por consecuencia de ciertos contratos mediante la tradición» (art. 609 del Código civil), actuando el instrumento público no como elemento ad solemnitatem, sino ad probationem, aunque devenga necesario para la inscripción en el Registro de la Propiedad, que a su vez, como se sabe, no opera en régimen de inscripción constitutiva, sino declarativa, salvo en algún derecho real, como la hipoteca; por otra parte, la escritura notarial no cubre todos los extremos del nego- 
cio jurídico plasmado en ella, puesto que el notario debe ser creído, sobre todo aquello que da fe de haber visto y oído al autorizar el instrumento: de visu et auditu suis sensibus, por lo que, de conformidad con lo dispuesto en el artículo 1.218 del referido Código civil, la jurisprudencia ha proclamado que así como las declaraciones hechas por las partes hacen prueba contra las mismas y sus causahabientes, en cambio, respecto de terceros no intervinientes, únicamente hacen prueba del hecho de que tales manifestaciones se han producido, pero no de su veracidad intrínseca, sólo protegida por una presunción iuris tantum. (Sentencias Sala 1.a, entre otras, de 5 de mayo, 25 de septiembre y 30 de octubre de 1956).

Considerando: Que en este caso, el tercero es la Administración pública, concretamente el Ayuntamiento de Marín, quien, por lo dicho, no puede verse perjudicado por actos de unos particulares con intereses contrapuestos a los de aquél, si en esos actos se contienen manifestaciones no coincidentes con la realidad, discordancia que la sola intervención del notario no puede sanar; el fiscal no sólo aparece como tercero, sino como un tercero de carácter privilegiado, por los intereses que defiende y representa mediante su equiparación al menor de edad; el Fisco, en el presente supuesto no puede ni debe pasar por una fecha, la expresada en el instrumento notarial de transmisión de los terrenos de que se trata, esto es, el 9 de diciembre de 1969, cuando bastantes meses antes la empresa compradora, aquí apelante, reconoció en diversos escritos ante el propio Ayuntamiento ser propietaria de los mismos.

ConsIDERANDo: Que por esta circunstancia la empresa contribuyente, como muy bien han proclamado los Tribunales que nos han precedido en vía administrativa y jurisdiccional, no puede pretender obtener unas deducciones por mejoras, realizadas antes del otorgamiento de la tan repetida escritura pública, pero después de la compra de este predio, por lo menos no posterior al 10 de enero de 1969, ya que en esta fecha existe constancia de escrito presentado ante el Ayuntamiento por esta sociedad, atribuyéndose la condición de propietaria del inmueble, puesto que, conforme a lo estatuido en el artículo 512-1 a) de la Ley de Régimen local, para la procedencia de deducir del valor fiscal -el valor corriente en venta al final del período impositivo- el importe de las mejoras permanentes será preciso que éstas se hayan realizado durante el mismo período impositivo y subsistentes al final del mismo, lo que, 
como hemos dicho, no ha ocurrido aquí; aparte de que las supuestas mejoras de pilotaje y afirmado no han sido otra cosa que las obras necesarias para la infraestructura de toda edificación de altura. (Sentencia de 7 de marzo de 1973, Ar. 1.051).

\section{Arbitrio de Plusvalfa: falta de aumento de Valor}

Estando comprendidas, tanto la fecha inicial como la final del período impositivo de autos, en un mismo índice valorativo, no se ha producido incremento alguno de valor para la parcela de referencia que pueda permitir la entrada en juego de la previsión establecida en el artículo 510 de la Ley de Régimen local, produciéndose así, ante la inexistencia de base imponible alguna por carencia de incremento legal de valor en los controvertidos terrenos, la imposibilidad de someterlos a tal tributación, trayendo ello, como definitiva consecuencia, la desestimación del recurso, con la paralela declaración de validez del acto recurrido, siguiendo así esta Sala el criterio, claramente establecido sobre el particular, por la sentencia de la Sala de lo Contencioso-administrativo de la Audiencia Territorial de Zaragoza, confirmada en este punto por otra del Tribunal Supremo de 3 de febrero de 1968, y sin que el problema ahora en estudio pueda tildarse de cuestión nueva, sino de nuevo motivo de oposición a la liquidación practicada por el Ayuntamiento de San Sebastián el 5 de septiembre de 1970, y en justificación de la pretensión de nulidad de la misma. (Sentencia de 24 de marzo de 1973, Ar. 1.428).

\section{ARbitrio DE PLUSVALfA: INDICES, APROBACIÓN}

Punto único a determinar es el referente al momento en que empiezan a producir sus efectos los índices aprobados por el Delegado de Hacienda de Guipúzcoa el 14 de julio de 1966, o bien a partir de tal fecha, o ya retrotrayendo su eficacia al 1 de enero de 1966, por tratarse de los índices trienales correspondientes a los años 1966, 1967 y 1968; pues bien, quedando fuera de toda controversia que la fecha en que se practicó la última tasación periódica para los terrenos de cuyo arbitrio se trata lo fue la de 31 de mayo de 1964, en cuyo momento regían los índices trienales correspon- 
dientes al período 1963, 1964 y 1965, como aprobados por el Delegado de Hacienda el 29 de diciembre de 1962, así como que la referida fecha de 31 de mayo de 1964 es la pertinente como inicial del período impositivo que nos ocupa, a tenor de lo al efecto previsto en el artículo 108-2 del Reglamento de Haciendas locales; esto sentado, la aprobación, al 14 de julio de 1966, de los índices trienales para 1966, 1967 y 1968 sólo puede operar a partir de tal momento, ya que sostener lo contrario sería tanto como pretender dar efecto retroactivo a tales índices, con desconocimiento de lo al efecto previsto en el artículo 61 de la Ley de Régimen local, así como en el artículo 223 del Reglamento de Organización, Funcionamiento y Régimen Jurídico de las Corporaciones locales y en el artículo 45-2 de la Ley de Procedimiento administrativo, por lo que hay que entender que hasta el 14 de julio de $1966 \mathrm{y}$, por tanto, al momento de la transmisión de autos en cuanto operada el 22 de marzo del mismo año, estaban vigentes los índices valorativos del trienio precedente, 1963, 1964 y 1965, tal como indubitadamente se deduce de la lectura del artículo 724 de la Ley de Régimen local. (Sentencia de 24 de marzo de 1973, Ar. 1.428).

\section{ARbitrio de plusvalfa: terRenos QUE tIENEN EL CONCEPTO DE SOLAR}

CoNSIDERANDo: Que el terreno estudiado cuya situación topográfica queda descrita en el anterior apartado cumple las condiciones o requisitos mínimos que para ser calificado de solar exige el artículo 499, apartado 1, de la Ley de Régimen local, por cuanto uno de sus lados forma línea de fachada con una vía pública urbaniza$\mathrm{da}$, considerando como tal a aquella o aquellas que tengan todos los servicios municipales, o por lo menos los de alumbrado, encintado de aceras o afirmado, y aunque la jurisprudencia, con base en la expresión en plural que emplea el precepto, exige como mínimo la concurrencia de dos servicios municipales para que una vía merezca tal conceptuación (sentencias de 18 de enero de 1970, 28 de junio de 1967, etc.), precisamente la aplicación de tal doctrina congruente con el principio que estima que el hecho imponible del arbitrio radica en el incremento de valor que experimentan los fundos, debido principalmente por la mejora urbana o por un destino no agrícola, etc., conduce a entender cumplidas, en este caso, tales 
exigencias al resultar indudable que la vía pública que forma el límite Oeste de la finca aparece dotada del servicio de afirmado y de alumbrado eléctrico, resultando indiferente a estos efectos que la carretera o vía pública tenga el carácter de carretera provincial, pues la titularidad dominical de la vía no resulta requisito presupuesto a los efectos de calificación de terreno como solar, dado que la norma equipara a las vías públicas (cuya calificación responde a un criterio de afectación o destino y no de titularidad) con las privadas, siempre que ambas merezcan la conceptuación legal de urbanizadas, aparte de que, como ha declarado la doctrina de la Sala con reiteración (sentencias, entre otras, de 10 de noviembre de 1966, 11 de diciembre de 1968, 9 de abril y 22 de mayo de 1969, 2 de mayo y 22 de noviembre de 1972, etc.), la razón o fundamento del arbitrio tiene una justificación más amplia que la que le atribuye la sentencia apelada, pues sin duda responde a múltiples factores, unos de evolución natural (crecimientos demográfico y económico, etc.), otros como consecuencia del planeamiento urbanístico o de otra índole, que llevan aparejados esfuerzos o inversiones, tanto estatales como de otras personas o entidades públicas o privadas que imponen el rescate para la colectividad (cuyo titular o beneficiario es el Municipio, por imperativo legal) de ese exceso de valor originado por causas ajenas al trabajo o esfuerzo de sus propietarios; en consecuencia, pues, la sujeción de la finca discutida al arbitrio del incremento del valor de los terrenos resulta patente al dejar establecida su condición legal de solar, en base de la declaración preceptiva y absoluta contenida en el apartado 1 del artículo 510 de la Ley de Régimen local. (Sentencia de 7 de febrero de 1973, Ar. 430).

\section{ARBITRIO SOBRE SOLARES SIN EDIFICAR: EXENCIÓN DE TERRENOS SOMETIDOS A PLAN DE REPARCELACIÓN OBLIGATORIA}

Merecen la conceptuación de exentos por aplicación de la norma contenida en el apartado 2 del artículo 504 de la Ley de Régimen local «los terrenos que aun teniendo la consideración de solares, según el artículo 499, no sean susceptibles de edificación por existir planes, ordenaciones o resoluciones administrativas que la prohiban", por ser claro que en tales supuestos (en los que tal vez la reparcelación obligatoria en la modalidad prevista en el aparta- 
do 2 a) del artículo 77 de la Ley es el ejemplo más típico) cesa la condición o requisito esencial para la aplicación del arbitrio examinado, dado su carácter no fiscal, cuya ratio descansa precisamente en el fomento de la edificación de los terrenos material y legalmente edificables. (Sentencia de 16 de marzo de 1973, Aranzadi 1.347).

9. CONTRIBUCIONES ESPECIALES: EXPEDIENTE ÚNICO PARA DIVERSAS OBRAS DE REPAVIMENTACIÓN

La inclusión de un solo expediente general de pavimentación de las calles de la población no puede considerarse sea por sí solo motivo de nulidad de pleno derecho, ya que de los artículos 451, 462 y 469, en relación con el número 3 del artículo 470, todos de la Ley de Régimen local, no se deduce una prohibición en ese sentido, sino que, antes al contrario, se permite a las Corporaciones emprender obras públicas, con cargo a estas contribuciones, comprensivas de la pavimentación de zonas completas de la población, como expresamente reconoce el artículo 29, apartado $a$ ), del Reglamento de Haciendas locales de 4 de agosto de 1952, precepto que interpretado rectamente permite que incluso la población entera pueda ser comprendida en un solo expediente de obras públicas, para ser posteriormente repartido el coste por contribuciones especiales, mientras en los módulos del reparto de las cuotas a los contribuyentes individuales se respetan los criterios que miden la diferente mejora que puedan obtener como resultado de la obra, siendo el sentido del número 3 del artículo 470 de la Ley de Régimen local, precisamente el opuesto al invocado por el Tribunal EconómicoAdministrativo, pues lo que dicho precepto establece es la indivisibilidad de los expedientes municipales de obras públicas, que han de financiarse por contribuciones de esta clase cuando la obra pueda dividirse en tramos, pero forma unidad técnica, y se comprenda en un proyecto único, en cuyo caso las diferencias de coste y utilidad de las diferentes partes de la obra que afecten inmediatamente a cada contribuyente no se imputan separadamente a éstos, sino que los beneficios y las cargas de la misma se reparten al conjunto de los contribuyentes comprendidos en el plan, como sucede en autos. (Sentencia de 23 de enero de 1973, Ar. 501). 


\section{CONTRIBUCIONES ESPECIALES: NO ES PRECISA LA APROBACIÓN DEL EXPEDIENTE POR El Delegado de Hacienda}

Carece de fuerza anulatoria el vicio denunciado de falta de aprobación del expediente de exacción por tal autoridad económica provincial, dado que el acuerdo municipal de imposición no sólo decide imponer las contribuciones, sino que ordena incorporar como documentación complementaria los proyectos técnicos de la obra y demás documentos exigidos en los que aparecen fijados con precisión los sujetos pasivos, los inmuebles afectados, las bases de percepción (superficie afectada determinada por los metros lineales de fachada en razón de 12 metros de fondo), el tipo de gravamen y posibles cuotas por inmueble, tanto por aumento de valor como por beneficio especial, etc., pudiendo afirmarse que los expedientes cumplen las exigencias mínimas que para procedimientos de este tipo preceptúan los artículos 16 y siguientes del Reglamento de Haciendas locales, debiendo destacarse la constitución en este caso de la Asociación administrativa de contribuyentes y de aparecer unidos al expediente los documentos a que se refieren los artículos 19 y 29 del citado Reglamento y cumplidos los trámites de publicidad y exposición al público que preceptúan los artículos 30 y 40 del Reglamento citado, por lo que, como dijo la sentencia de la Sala de 12 de marzo de 1971, al resolver un supuesto análogo, el expediente no precisaba la aprobación del Delegado de Hacienda, sino que únicamente se elaborase conforme a los trámites senalados en el Reglamento, porque existiendo Ordenanza es indiscutible que el expediente se convierta en un acto de cumplimiento de lo dispuesto en aquélla, bastando que en el mismo consten los documentos referentes a la obra a realizar, presupuesto, fijación de base, relación de fincas y de beneficiarios, cuotas individuales exigibles, etc. (Sentencia de 3 de marzo de 1973, Ar. 994).

11. DEREchos y taSAS: RECogida de basuras, EXENCIÓN Banco DE ESPAÑA

Considerando: Que en contra de la exención se ha alegado por el Ayuntamiento que el término gravamen empleado por el precepto del citado Decreto-ley no comprende el concepto de tasa muni- 
cipal por tener ésta una naturaleza específica dentro del cuadro de las exacciones municipales conforme al artículo 434 de la Ley de Régimen local de 24 de junio de 1955, y por su parte la sentencia apelada niega la exención por el carácter de contraprestación propio de la tasa que impide incluir este concepto fiscal en la exención concedida no obstante el empleo de expresiones como «de toda clase» y "demás», ya que estima se debe interpretar la exención como referida únicamente a la categoría tributaria caracterizada por su exigibilidad general, ajena a la idea de contraprestación que va unida al principio de justicia conmutativa y, por tanto, los tributos, como las tasas y contribuciones especiales que participan por su naturaleza de esa idea de contraprestación, son conceptos extraños a la exención fiscal concedida.

CONSIDERANDO: Que en cuanto a la argumentación contenida en la sentencia apelada que excluye de la exención discutida los conceptos tributarios como las tasas que entrañan la idea de una contraprestación a cargo del órgano que exige la tasa, es de tener en cuenta que, aunque inspirada en un fundamento de equidad muy razonable, éste es más acuciante en las relaciones de Derecho privado que en las de Derecho tributario, en las que si bien en principio es también operante esta distinción en general, debe ceder con carácter excepcional en supuestos como el presente, en que no puede dudarse del alcance y extensión de la exención concedida que comprende toda clase de gravámenes, entre los que hay que incluir el representado por la tasa municipal debatida de recogida de basuras, pues esta interpretación en que el término gravamen se emplea en su acepción genérica o usual es conforme con el artículo 23 de la Ley General Tributaria, que en defecto de expresa definición en la norma se remite al sentido jurídico, técnico o usual según proceda, máxime cuando los artículos 436 y 442 de la Ley de Régimen local aluden a los derechos y tasas con el término genérico de gravámenes, por lo que claramente se infiere que la exención enunciada tan ampliamente en el precepto debatido ha de comprender también las tasas municipales, ya que alude a los gravámenes del Estado, Provincia y Municipio, dando a entender la intención de incluir en la exención todo tributo, cualquiera que sea su naturaleza.

Considerando: Que la propia Ley de Régimen local vigente prevé en su artículo 721 la concesión por el Estado de la exención de 
derechos, tasas y arbitrios provinciales y municipales a alguna empresa o entidad, subrogándose el Estado en la obligación de pagar su importe a la Corporación local respectiva, salvo disposición legal en contrario, por lo que puede afirmarse que dicha Ley contempla expresamente la posibilidad legal de una exención que comprenda no sólo los tributos de carácter general, sino también aquellos que impliquen una contraprestación, como ocurre con las tasas municipales por determinados servicios. (Sentencia de $7 \mathrm{de}$ febrero de 1973, Ar. 429).

\section{LIQUIDACIONES PROVISIONALES: RECURSOS CONTRA LAS MISMAS}

Las liquidaciones provisionales que giran los Ayuntamientos en aplicación de las exacciones locales son reclamables ante la jurisdicción económico-administrativa, lo dice, con carácter genérico, la letra a) del artículo $165 \mathrm{de}^{\prime}$ la Ley General Tributaria, que incluye en ese ámbito de la reclamación económico-administrativa «las liquidaciones provisionales o definitivas, con o sin sanción" y lo reiteran de manera específica la letra $e$ ) del artículo $1 .^{\circ}$ del Reglamento de 26 de noviembre de 1959, que declara reclamables los actos de «aplicación y efectividad de las exacciones de las Haciendas locales...", y la letra a) del apartado 1 del artículo 44 del mismo Reglamento, que establece la inadmisibilidad de las reclamaciones dirigidas contra los actos que "provisional o definitivamente reconozcan o designen un derecho o declaren una obligación" y lo ratifican los artículos 727 de la Ley de Régimen local y 238 del Reglamento de Haciendas, y que estas liquidaciones pueden ser a elección del contribuyente reclamadas directamente o utilizando el previo recurso de reposición lo abona el mismo artículo $72 \overline{7}$ citado al configurar dicho recurso como potestativo, declaración que reitera el artículo 131 del Reglamento de Hacienda municipal de Madrid, qué, además, en su artículo 132 dispone que "se entenderá tácitamente desestimado cuando no se haya practicado notificación expresa de la resolución recaída dentro de los quince días siguientes a la fecha de su interposición" y en su artículo 133 "que el recurso de reposición interrumpe el plazo de interposición de la reclamación económico-administrativa, que volverá a contarse de nuevo a partir del día en que se entienda tácitamente desestimado", y todos estos preceptos evidencian el error en que incurre el Tribunal Económi- 
co al declararse incompetente para conocer de la reclamación interpuesta por los recurrentes contra una liquidación provisional girada por el Ayuntamiento, en la que se utilizó por aquéllos el recurso previo de reposición que no fue objeto de expresa resolución, pues no es exacto, según dichos preceptos, que las liquidaciones provisionales sólo pueden ser impugnadas ante el Ayuntamiento, ni que efectuada esta impugnación sea imprescindible la existencia de un acto resolutorio expreso para acceder a la vía económico-administrativa, sin que pueda acudirse a ésta directamente, y si no se hace así y se interpone previamente la reposición ante el Ayuntamiento debe estimarse ésta tácitamente resuëlta cuando no se efectúa notificación de resolución dentro de los quince días siguientes a su presentación. (Sentencia de 20 de marzo de 1973, Ar. 1.352).

\section{ORdENANZAS fiscales: falta DE BASE PARA SU IMPUGNaCióN}

ConsIDERANDo: Que si el recurso contencioso-administrativo sólo puede prosperar cuando el acto o la disposición que sea su objeto incurra en infracción del Ordenamiento jurídico, habrá que rechazar sin más razonamiento cuantas pretensiones de las aquí ejercitadas por la Cámara de la Propiedad Urbana de Madrid se dirijan a un perfeccionamiento, según su punto de vista, de las Ordenanzas impugnadas o a una disminución de la presión fiscal, pero no a lograr un sometimiento de los preceptos de aquéllas a normas o principios de categoría superior, porque, como ya dio a entender la sentencia de esta Sala de 13 de noviembre de 1972, no puede pretenderse de los Tribunales el ejercicio subsidiario de la potestad reglamentaria, y sí tan sólo que sea respetado el principio de legalidad cuando la Administración ejercita aquella potestad. (Sentencia de 22 de marzo de 1973, Ar. 1.423).

\section{JURISDICCION CONTENCIOSO-ADMINISTRATIVA}

\section{Previo Pago: aval bancario}

Existe en las últimas sentencias del Tribunal Supremo una cada vez más acusada tendencia a facilitar el proceso contencioso-administrativo, y al efecto se equipara el aval bancario con el previo 
pago, exigido como condición habilitante del recurso contencioso si los términos del aval vienen configurados con tal amplitud que aseguren suficientemente los intereses del Fisco. (Sentencia de 28 de febrero de 1973, Ar. 745).

\section{SUSPENSION DE ACUERDO MUNICIPAL: IMPROCEDENCIA}

Considerando: Que, como consecuencia de lo dicho, los factores a conjugar aquí son los siguientes: a) principio general de ejecutoriedad del acto administrativo, constantemente proclamado por el legislador, por la doctrina científica y por la jurisprudencia; b) posibilidad de neutralización de dicho principio, precisamente a través de la vía incidental en que nos encontramos (arts. 122-125 de la L. J.), en los supuestos en que de la ejecución del acto administrativo se produjeran daños o perjuicios de «reparación imposible o difícil»; c) no consideración por la jurisprudencia de que son de difícil o imposible reparación aquellos que puedan ser traducidos, con cierta aproximación, como ocurre en el campo del Derecho, a un valor económico, expresado en términos monetarios; d) presunción de que la Administración pública, aunque para el cumplimiento de sus compromisos financieros pueda presentar problemas, por los trámites a cumplir, ante obligaciones imprevistas en el planeamiento general, en definitiva, siempre ofrece suficiente solvencia para cumplir los mismos, lo cual se ha destacado con cierto énfasis tratándose de Municipios de ciudades importantes. (Sentencia de 15 de febrero de 1973, Ar. 509).

\section{POLICIA MUNICIPAL}

\section{Autotaxis: anUlación DE licencia}

Del examen de las actuaciones seguidas por el Ayuntamiento de Lousame, que culminaron en los acuerdos recurridos por los que la Permanente anuló la licencia municipal de autoturismo concedida con el número 10 al recurrente, por estimar que dejó de prestar servicio más de tres meses consecutivos y haber vendido la licencia y el coche a un vecino de Noya, en cuyo término municipal presta desde entonces el servicio, es incuestionable que tanto en el 
supuesto que ese acuerdo municipal se considere anulatorio de la licencia, que es como el mismo se califica, o sea declaratorio de caducidad de la licencia, que es como lo califica el abogado del Estado en su escrito de contestación a la demanda, lo cierto es que el Reglamento de 4 de noviembre de 1964, en sus artículos 18, 21 y 24 , exige en todo caso, es decir, en cualquier supuesto en que se decrete la pérdida de la titularidad de estas licencias municipales por anulación o por caducidad, la apertura de un expediente en el que ha de justificarse plenamente la causa o motivo en que se basa la Corporación como fundamento del acuerdo de su incoación siendo preceptivos los trámites de audiencia del titular a quien se le priva de la licencia municipal y del Sindicato Provincial -Grupo Provincial de Autotaxis- de que aquél forma parte, pues en los expedientes de esta naturaleza hay que distinguir entre la declaración administrativa de que se inicie y tramite el expediente de caducidad o de nulidad y la posterior resolución del mismo, que no se produce automáticamente, sólo por la denunciada o porque la Corporación, de oficio, que es el caso de autos, haya observado la concurrencia de unos hechos que obliguen a que se tramite expediente, sino que es sólo después, teniendo en cuenta las circunstancias del caso, cuando la Corporación podrá terminar el expediente declarando si se demostró plenamente o no la causa de caducidad o de anulación de la licencia, pero para llegar a esta declaración es necesario que se hayan cumplido los trámites esenciales que el citado Reglamento establece en los preceptos que ya se dejan señalados que son garantías procesales de respeto a los intereses afectados. (Sentencia de 8 de marzo de 1973, Ar. 1.053).

2. Fiscalf́a de la Vivienda: lf́mites de competencia CON EL Ayuntamiento

CONSIDERANDO: Que ha sido constante preocupación de estè Tribunal la de mantener con la posible y suficiente precisión la diferencia entre las atribuciones de las Fiscalias de la Vivienda, como órganos locales de la Dirección General homónima en el Ministerio de igual título, y las de los Ayuntamientos, como Corporaciones locales dotadas de amplias facultades en materia urbanistica; $y$ con tal fin ha especificado que la acción de las primeras se centra y limita en las condiciones de habitabilidad de las viviendas, atendidas sus circunstancias higiénico-sanitarias, pensando en la salubridad 
de los moradores, mientras que los Ayuntamientos, además de una potestad concurrente con la expuesta, ejercitada con ocasión de su actividad de policia urbana, poseen potestades mucho más importantes relacionadas con la seguridad de las viviendas y de los inmuebles a que pertenecen, así como de su encuadramiento de las situaciones de ordenamiento y planificación urbanisticos que les resulten aplicables; pues tal resulta, de una parte, del estricto y no ampliable contenido de los artículos 1 y 5 del Decreto de 23 de noviembre de 1940, en relación con el primero del 3 de octubre de 1957, y de otra de los artículos 101 de la Ley de Régimen local y 168 y 170 de la Ley de Régimen del Suelo. (Sentencia de 23 de marzo de 1973, Ar. 1.288).

\section{EDIFICIOS RUINOSOS: CONSTRUCCIONES FUERA DE ALINEACIÓN}

Considerando: Que la causa del apartado $c$ ), núm. 2, del artículo 170 de la Ley del Suelo, que contempla un supuesto de ruina urbanística, ha sido interpretada por reiterada jurisprudencia (sentencias de 7 de marzo de 1961, 4 de noviembre de 1963, 30 de junio de 1965, 20 de diciembre de 1968, etc.) en el sentido de que una de las circunstancias urbanisticas que aconsejan la demolición de los inmuebles es la de existir en él daños cuya reparación hubiere de ocasionar obras de consolidación, modernización o incremento de valor de los edificios situados fuera de las alineaciones oficiales, ya que una circunstancia de esta naturaleza hace que, por hallarse prohibidas tales obras como regla general por el artículo 48 de la Ley de 12 de mayo de 1956, los inmuebles, al quedar en peligro de derrumbamiento, han de ser considerados ruinosos, consiguiéndose la medida de policia y seguridad edilicia y de fomento de la edificación a que oledecen las citadas normas, y por consiguiente, cuando se discute una ruina de este tipo, como sucede en autos, es inaplicable el párrafo $3 .^{\circ}$ del artículo 48 mencionado que permite a la Administración, en casos excepcionales, autorizar obras de consolidación en edificios fuera de las alineaciones, cuando no estuviere prevista su expropiación en el plazo de quince años, a contar de la fecha en que se pretenda realizarlas, ya que este precepto se refiere al caso opuesto al debatido, cuando es el dueño de la finca en tales condiciones quien pretende obtener una licencia municipal de obras que tienden a prolongar la vida del inmueble, pero no si se trata de conseguir la declaración de ruina, pues la jurispru- 
dencia ha declarado al respecto que no se puede obligar a los propietarios a realizar obras antieconómicas en edificios fuera de ordenación (sentencia de 24 de marzo de 1958), y de ahí que la cuestión deba centrarse, como hace la propia Administración, en determinar si son obras de consolidación las exigidas para mantener la finca en estado de utilización. (Sentencia de 12 de febrero de 1973, Aranzadi 717 ).

\section{EDIFICIOS RUINOSOS: OBRAS DE CONSERVACIÓN}

CONSIDERANDO: Que el deber de conservación de su finca, que incumbe al propietario, establecido en el articulo 168 de la Ley citada, tiene un limite, que resulta infranqueable, fuera del cual no se pueden acordar obras a cargo del mismo (art. 169-2 id.) y que determinan (arts. 168 y 170 id. y sentencias del Tribunal Supremo de 29 de noviembre de 1968 y 17 de octubre de 1970) que si lo procedente es la ruina, no pueden imponerse al propietario obras de reparación (art. 170-2-b); pues en los supuestos de ruina cesa el deber de conservación; aspecto de la cesión que no hay que silenciar, pues la ruina, en la estimativa que tiene en la Ley del Suelo, no es hoy sólo una cuestión de policía de seguridad, sino que constituye también un limite al deber de conservación, de tal suerte que, de no darse los supuestos legales de ruina, tiene que ordenarse la realización de las obras precisas para mantener las condiciones de seguridad, salubridad y ornato público, como dice el artículo 168 de la Ley del Suelo, alternativa que se refleja en el acuerdo recurrido; pues en el mismo se ordenó a los recurrentes que procediesen, dentro del plazo de un mes, a solicitar la oportuna licencia de «reparación" del inmueble, orden que en el terreno legal no es procedente, pues las reparaciones exceden del 50 por 100 del valor del edificio; $y$ no cabe alegar contra esta resultancia que la situación de abandono en que se encuentra haya sido por desidia del propietario, ya que las responsabilidades en que pudiera haber incurrido son ajenas al expediente de ruina (sentencias de la Sala $4 .^{\mathrm{a}}$ de 22 de junio de 1959, 4 de noviembre de 1963, 22 de diciembre de 1965, 11 de abril de 1966, 14 de enero y 14 de abril de 1967), bastando que se acrediten los daños, ya que la alegación versa. sobre cuestión civil (sentencias de 22 de junio de 1959 y 4 de noviembre de 1963), procedimiento que no siguieron los inquilinos de los pisos, que hace años los abandonaron. (Sentencia de 26 de febrero de 1973, Ar. 879). 


\section{PROCEDIMIENTO ADMINISTRATIVO}

\section{INFRACCIÓN DE LA NORMA RITUARIA}

CONSIDERANDO: Que no toda infracción rituaria acarrea inexorablemente la nulidad de las actuaciones administrativas producidas, sino que tal efecto únicamente se origina cual proclama el artículo 293 del Reglamento de Organización de las Entidades locales cuando los vicios son esenciales o producen indefensión, siendo, pues, a la luz de esta doctrina consagrada asimismo por el artículo 48 de la Ley de Procedimiento administrativo, y jurisprudencia reiterada, cómo han de ser enjuiciados los defectos procedimentales imputados, determinando al propio tiempo que su concurrencia o ausencia, la trascendencia que en su caso haya podido tener respecto del adecuado pronunciamiento de la voluntad administrativa y de la legítima defensa de los derechos e intereses de los contribuyentes afectados, sin olvidar, en fin, que el pronunciamiento anulatorio deviene también improcedente, cuando la lógica prevé que la reproducción de las actuaciones conducirán a idéntico resultado. (Sentencia de 26 de marzo de 1973, Ar. 1.429).

2. RECLAMACIÓN ECONÓMICO-ADMINISTRATIVA: FALTA DE LEGITIMACión aCtiva DE UN AyUntamiento

Considerando: Que la primera cuestión - de índole formalque ha de decidir la Sala respecta a la legitimación activa del Ayuntamiento recurrente, hoy apelado, para interponer la reclamación económico-administrativa, legitimación que le había negado el citado Tribunal Provincial en su acuerdo impugnado de 30 de octubre de 1970, lo que constituyó uno de los fundamentos que tuvo dicho Tribunal para confirmar la liquidación controvertida; y si al respecto se tiene en cuenta que la obligación tributaria fue contractualmente aceptada por la mencionada Corporación municipal en la escritura pública que originó la liquidación cuestionada, en la que se expresaba (estipulación $6 .^{\mathrm{a}}$ ) que todos los gastos, impuestos y arbitrios que pudiera originar el otorgamiento serían satisfechos por el Ayuntamiento, es visto que éste carecía de la necesaria legitimación para iniciar la vía económico-administrativa, y ello en 
aplicación del artículo 35-2, apartado d), del Reglamento de 26 de noviembre de 1959 de Procedimiento para las reclamaciones económico-administrativas, a cuyo tenor no estarán legitimados para promoverlas los que asuman obligaciones tributarias en virtud de contrato, precepto posteriormente ratificado por el artículo 167, apartado $d$ ), de la Ley General Tributaria, de 28 de diciembre de 1963, que también con el claro y sólido fundamento de la necesidad de impedir la evasión fiscal, igualmente niega legitimación para las reclamaciones económico-administrativas a quienes asuman aquellas obligaciones mediante pacto o contrato.

En todo caso ha de tenerse en cuenta que reiterada jurisprudencia de la Sala (por ejemplo, sentencias de 14 de diciembre de 1965,16 de abril de 1968 y 14 de marzo de 1970) ha proclamado que la concepción de la legitimación administrativa no es exactamente coincidente con la contencioso-administrativa. (Sentencia de 22 de marzo de 1973, Ar. 1.421).

\section{RESPONSABILIDAD ADMINISTRATIVA}

Profundos baches no SEÑalizados en CaRretera provincial

Considerando: Que en examen ya de la cuestión de fondo no se advierte la razón para afirmar que la responsabilidad civil de las Corporaciones locales se atiene a otras reglas de fondo que la atribuible a la Administración General del Estado, pues bien claramente disponía el artículo 133 del Reglamento de Expropiación forzosa, en su párrafo 2, que «las Corporaciones locales y Entidades institucionales quedan sujetas también a la responsabilidad que regula este capítulo». En consecuencia, responden de toda lesión que sufran los particulares «a consecuencia del funcionamiento normal o anormal de los servicios públicos", como previene el artículo 121 de la Ley de Expropiación forzosa y reitera la Ley de 26 de julio de 1957. $Y$ dificilmente podría estimarse normal la existencia de grandes baches en la carretera durante varios dias, sin que proceda a su señalización hasta después de ocurrido un accidente, máxime cuando ello responda a un deficiente régimen de personal. Efectivamente, en el informe de la Sección de Vías y Obras, posterior al hecho de autos, se decía a la Diputación el 20 de enero de 1968 que "en el tramo del camino provincial en que se ha 
producido el accidente existía hasta hace unos tres años un caminero. Este caminero, desmoralizado, como tantos otros, por prolongarse su situación de interinidad, por no percibir ni siquiera el jornal mínimo que prescriben las disposiciones laborales vigentes y por las corrientes anticaminero que ahora rigen, dejó el servicio. Ocioso es decir que ni siquiera se ha intentado proponer la provisión de la vacante dejada por el citado caminero". (Sentencia de 8 de febrero de 1973, Ar. 622).

\section{SOLARES E INMUEBLES DE EDIFICACION FORZOSA}

\section{Competencia para acordar la inclusión en El Registro}

Considerando: Que en cuanto a la competencia de la Comisión Municipal Permanente y no el Pleno del Ayuntamiento para acordar la inclusión de la finca en el Registro de Solares, es de ver que, aunque fuese de aquélla y no de ésta la referida facultad, al estar integrada dicha Comisión municipal en el Pleno del Ayuntamiento, es claro que tomado el acuerdo recurrido por un órgano que abarca y asume al estimado competente, no puede producirse la nulidad que se reclama, ya que son mayores las garantías que suponen la adopción de la resolución por todo el Ayuntamiento que por una parte de él. (Sentencia de 10 de febrero de 1973, Ar. 671).

\section{EDIFICACIONES INADECUADAS}

CoNSIDERANDo: Que la argumentación apelante sobre no desmerecer comparativamente la vivienda referenciada, en cuanto a la altura corriente de las de su zona natural, queda suficientemente rebatida con la apreciación contraria derivada de los elementos probatorios obrantes en el proceso, pero a mayor abundamiento conviene puntualizar que no es al administrado a quien la Ley faculta para delimitar subjetivamente con el apelativo de natural la zona que ha de relacionarse como término en juicio comparativo, y que tampoco es posible requerir la-ásignación en todo caso de un número mayoritario al subconjunto de edificaciones de mayor altura que la objeto de parangón, pues el criterio legal no consistió en establecer, como pudo hacerlo, un preciso dato estadístico cuando 
empleó la palabra corriente, sinónima de normal o frecuente, sino que ideológicamente relacionada con el fin de mejoramiento urbano deseado que inspira la materia, corresponderá referir su sentido a la estimativa de un número de frecuencias de altura autorizada con suficiente entidad para apreciar consolidado en la zona el proceso de mejoramiento referido, $y$ entender por zona a estos efectos comparativos la circundante sujeta a las mismas normas urbanisticas incluyentes de aquel objetivo, general o parcialmente planificado, o inspirador de las Ordenanzas vigentes para lograr la mejora de la situación actual, lo que implica asimismo orientar la comparación de altura hacia la autorizada por las Ordenanzas de cara al futuro, ya que ceñirse a la realidad presente, como pretende el apelante, haria difícil emprender, y más aún conseguir, la promoción urbanistica como factor de desarrollo comunitario. (Sentencia de 31 de marzo de 1973, Ar. 1.389).

\section{URBANISMO}

\section{ARBITRIO SOBRE AUMENTO DE EDIFICABILIDAD}

ConSIDERANDO: Que la cuestión básica y fundamental planteada en la litis, que por cierto se mantiene intacta en la presente apelación, consiste en determinar si es o no susceptible de ser gravado con el arbitrio establecido por el artículo 187 de la Ley del Suelo el aumento de volumen de edificabilidad operado en relación con un terreno (el del polígono 128 de Hernani), como consecuencia de su conversión de suelo rústico en urbano, con el consiguiente incremento del coeficiente de edificación, al amparo del nuevo Plan Parcial relacionado con dicho polígono, aprobado definitivamente el 30 de septiembre de 1969; así como de las limitaciones legales de esta propiedad, por obra de la acción planificadora, no surgen derechos a indemnizaciones para los propietarios afectados, por la misma razón, de las expectativas y ventajas que la ordenación del territorio produzca a los mismos, normalmente no deben derivarse cargas, como la tributaria en controversia; sin embargo, como vimos antes, existe un arbitrio, al que ya nos hemos referido, y que es aplicado por la Corporación apelante, que permite hacer tributar por los aumentos de volumen de edificación, pero, y aquí está el quid de la cuestión, o la ratio legis de la misma, el arbitrio opera no en función de las delimitaciones del respectivo Plan, sino en 
las modificaciones que se introduzcan en el mismo, al amparo de lo autorizado en el repetido artículo 46 de la Ley del Suelo, productoras de esas posibilidades de aumento del volumen edificable.

Considerando: Que en el caso de autos el aumento de edificabilidad experimentado por los terrenos comprendidos dentro del sector acotado urbanísticamente como polígono industrial núm. 128 de la villa de Hernani no se ha producido por una modificación singular de un Plan anterior, sino muy distintamente porque a esos terrenos ha llegado una planificación que hasta ahora no existía, y, por tanto, como con pleno acierto ha resuelto la Sala de Pamplona, no es procedente el devengo del arbitrio municipal de que se trata; en efecto, ha sido por obra del Plan Parcial aprobado el año 1969 (inicialmente el 6 de mayo y de forma definitiva el 30 de septiembre), que a su vez ha desarrollado el Plan General de la mencionada población (con aprobación inicial el 30 de agosto de 1968 y definitiva el 22 de julio de 1970), por lo que los terrenos en cuestión han pasado, automáticamente, de su anterior condición de rústicos a la de urbanos, con la consiguiente transformación y beneficios; todo ha sido obra de una planificación ex novo, que es lo que impide aplicar al presente supuesto lo establecido en el repetido artículo 187 de la Ley del Suelo. (Sentencia de 17 de marzo de 1973, Ar. 1.350).

\section{Nulidad DE LiCENCIA DE CONSTRUCCIÓN EN ZONA VERDE}

CONSIDERANDO: Que admitiéndose de una manera expresa en el acuerdo adoptado por la Comisión de Planeamiento y Coordinación del Area Metropolitana de Madrid el 15 de julio de 1966, que la edificación de la subcentral solicitada por la Unión Eléctrica Madrileña, S. A., en el Barrio de la Concepción de dicha capital disminuye en 480 metros cuadrados la extensión de los terrenos dedicados a espacios libres y calles, es evidente que la referida resolución infringe lo dispuesto en los artículos 45 y 47 de la Ley sobre Régimen del Suelo y Ordenación Urbana, de 12 de mayo de 1956, conforme a los cuales tanto la Administración como los particulares quedan obligados al cumplimiento de los Planes aprobados, sin que pueda apartarse el uso de los predios del destino previsto ni efectuarse nuevas construcciones que no se ajusten a la ordenación 
aprobada, así como también infringe lo establecido en el artículo primero de la Ley de 2 de diciembre de 1963, que preceptúa que una vez aprobados los Planes de Ordenación Urbana y los Proyectos de Urbanización no podrá introducirse en ellos ninguna clase de modificación que tuviere por objeto una diferente zonificación o uso urbanístico de las zonas verdes o espacios libres previstos en el Plan sin cumplir los requisitos prevenidos en dicha Ley, que, entre otros, exige en el apartado 2 de ese mismo artículo que la modificación sea aprobada por Consejo de Ministros, previo informe favorable del Consejo de Estado y de la Corporación municipal interesada con el quórum del artículo 303 de la Ley de Régimen local, cuyas circunstancias es manifiesto no concurren en el presente caso. (Sentencia de 26 de febrero de 1973, Ar. 876).

3. Terreno No edificable: transcurso del Plazo de diez aÑos Sin EXPROPIAR

Considerando: Que el artículo 56 de la Ley del Suelo preceptúa que «la expropiación e imposición de servidumbre sobre los terrenos que no resultasen edificables por sus propietarios particulares, habrá de llevarse a efecto dentro del plazo máximo de diez años, a contar de la fecha de entrada en vigor del Plan que las motivare», añadiendo que «si no se hubiese procedido a la expropiación o imposición de servidumbres en el plazo indicado, el propietario podrá requerir a la Administración para que lo efectúe en el de los tres meses siguientes, y si no se llevare a cabo recobrará el libre ejercicio de sus facultades dominicales"; y el expediente acredita: que el terreno objeto del litigio quedó afectado por el Plan o Proyecto redactado por la Comisión General para la Ordenación Urbana de Madrid, aprobado por el Consejo de Ministros de 26 de octubre de 1956 ( $B$. O. del Estado del día 14 de noviembre siguiente), con la denominación de Proyecto de expropiación del sector de Orcasitas; y que los hoy recurrentes, insistiendo en la petición que a la Administración había dirigido la anterior propietaria de la finca Compañía Mercantil Hutchinson, solicitaron de la Comisión del Area Metropolitana, en 4 de enero de 1967, y de la Gerencia de Urbanismo, en 6 de marzo de 1968, que se les permitiese recobrar el libre ejercicio de sus facultades dominicales, precisando en el último de los escritos mencionados que habían transcurrido más 
de once años desde el acuerdo del Consejo de Ministros sin que se hubiese iniciado la expropiación, y más de tres meses desde su anterior petición, y como efectivamente no resulta acreditado que haya propietario de la finca, es inexcusable concluir, como el propio Abogado del Estado, Asesor Jurídico de la Comisión del Area Metropolitana de Madrid, informó a ésta (folios 23 a 25 del expediente), que los demandantes tienen reconocido por el artículo 56 de la Ley del Suelo el derecho que ejercitan, pues transcurrieron diez años de inactividad de la Administración y se ha formulado por los propietarios el requerimiento prevenido en dicho precepto -que como se dijo en las sentencias de 23 de noviembre de 1968 y 27 de enero de 1971 no precisa formalismo especial-, sin que la Administración haya llevado a cabo la expropiación. (Sentencia de 21 de febrero de 1973, Ar. 511).

\section{ZONA MARITIMO-TERRESTRE}

\section{DESLINDE}

Considerando: Que es densísima la jurisprudencia dictada por esta Sala del Tribunal Supremo en materia de deslinde de zonas marítimo-terrestres, de la cual se han extraído a su vez dictámenes emitidos por la Dirección General de Puertos y que en resumen (sentencias, entre otras, de 22 de mayo de 1961, 7 de marzo de 1966, 16 de marzo de 1968, 23 de enero de 1969, 16 de octubre de 1970, 25 de febrero de 1971 y 3 y 16 de mayo de 1972) establecen la doctrina de que los deslindes administrativos de las zonas marítimoterrestres no resuelven más que un problema de límites, es decir, la determinación de hasta donde llegan éstos, sin poder hacerse declaraciones sobre derechos de propiedad particular, porque tal facultad es propia de los Tribunales de la jurisdicción ordinaria, y tras este principio general, el de que las Ordenes ministeriales en las que se plasma la delimitación contienen un acto administrativo que es la aprobación del deslinde y amojonamiento, que si fue consentido por los actores, es dudoso que los mismos puedan posteriormente impugnar tales límites, no obstante lo cual, y al entrar en la legislación sustantiva constituida por la Ley de Puertos de 1928, se hace preciso afirmar que su artículo $10^{\circ}$ define la zona marítimo-terrestre como el espacio de las costas o fronteras maríti- 
mas del territorio español que baña el mar en su flujo y reflujo, en donde son sensibles las mareas, y las mayores olas en los temporales, en donde no lo sean; es decir, que la determinación de la zona marítimo-terrestre es una cuestión puramente de hecho que tiene la virtud de convertir esos terrenos delimitados en terrenos de dominio y uso público, pero sin perjuicio de los derechos que a los particulares puedan corresponder y, en definitiva, en las últimas sentencias citadas, que si en el acta de deslinde o amojonamiento no se ha hecho protesta por el propietario interesado, la pretensión posterior equivale a sustituir el criterio de los técnicos representantes de los Ministerios por otro subjetivo, pues la referencia que en el artículo $7 .^{\circ}$ de la repetida Ley se hace a los terrenos de propiedad particular, colindantes con el mar o enclavados en la zona marítimo-terrestre, significa que los mencionados conceptos establecen una presunción iuris tantum del carácter de bienes y dominio nacional de uso público, la cual no puede obstar, por su expresado peculiar carácter, a la prueba en contrario a la existencia en aquélla de los terrenos de propiedad privada, prueba que ha de recaer sobre el accionante por imperativo de los principios generales rectores del ordenamiento jurídico, de aplicación a esta jurisdicción, y como es visto en el presente caso, dicha prueba quiebra en cuanto a los derechos alegados, y en todo caso quedan a salvo dichos derechos por los términos en que se ha expresado la resolución recurrida. (Sentencia de 28 de marzo de 1973, Aranzadi 1.452$)$.

\section{DESLINDE: OTRA SENTENCIA}

Otra sentencia sobre deslinde en zona marítimo-terrestre es la de 7 de marzo de 1973. (Ar. 1.052). 
